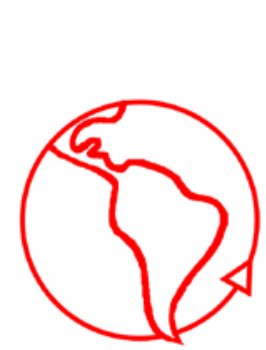

\title{
Resumen sintético del sistema social de la ciencia según Niklas Luhmann
}

\author{
A synthesis of the Social System of Science according to Niklas \\ Luhmann
}

Gerardo D. Sánchez Romero

University of Copenhagen, Dinamarca.

\begin{abstract}
Resumen
El siguiente texto presenta a la ciencia como un sistema social a la luz de la organización conceptual de la teoría de los sistemas funcionalmente diferenciados de Niklas Luhmann, utilizando para tal fin una exposición monográfica que desarrolla puntualmente algunos de los planteamientos básicos que desempeñan un rol crucial en la explicación de este subsistema de función. Así, el texto está dividió de la siguiente manera: 1) Conocimiento; 2) Verdad; 3) La ciencia como sistema social; 4) Reducciones correctas y; 5) Ciencia y sociedad, en donde en cada apartado se desprenden elementos conceptuales intrínsecos tales como los de observación, realidad, reflexión, crédito, jerarquía, hipótesis, clausura operativa, teorías, métodos, publicaciones, disciplinas y acoplamientos estructurales, dando forma a la arquitectura teórica que interpreta a la ciencia como sistema social en la sociedad.
\end{abstract}

\begin{abstract}
The following present science as a social system in the light of the conceptual organization of the theory of functionally differentiated systems of Niklas Luhmann by using a monographic exposition capable to develop some of the basic approaches that play a crucial role in the explanation of this functional subsystem. Hence, the text is divided as follows: 1) Knowledge, 2) True 3) Science as a social system, 4) Accurate reductions and, 5) Science and society, where in each section emerge intrinsic conceptual elements as: observation, reality, reflection, trust, hierarchy, hypothesis, operational closure, theories, methods, publications, structural drifts and disciplines, all of them shaping the theoretical architecture that interpret science as a social system within the society.
\end{abstract}

Palabras Clave: conocimiento, verdad, ciencia, autología, autopoiesis

Keywords: knowledge, true, science, autology, autopoiesis

\section{Introducción}

La empresa sociológica de Niklas Luhmann dedicó gran parte de sus análisis a algunos de los subsistemas que están inscritos en el plano de la diferenciación funcional orientada por los medios simbólicamente generalizados. De esa manera en su obra podemos encontrar estudios referentes a los diversos sub-sistemas de función, como son el arte, el derecho, la política, la economía, la religión, el amor, y para los fines de nuestro escrito: la ciencia. ${ }^{1}$ De esta manera, el texto sobre el cual está orientado este capítulo será, como es presumible, $L a$

\footnotetext{
${ }^{1}$ En obras como El arte de la sociedad; El derecho de la sociedad; Luhmann, la política como sistema; La economía de la sociedad; Sociología de la religión y El amor como pasión, respectivamente; textos disponibles en lengua castellana.
} 
ciencia de la sociedad (Luhmann 1996), una obra tardía en la bibliografía de Luhmann² que desarrolla de manera elegante los elementos básicos del fenómeno del conocimiento verdadero.

"Con el título de la Ciencia de la Sociedad queremos indicar que la ciencia no será aquí tratada como un observador que oscila libremente sobre el mundo, sino como una empresa de la sociedad que produce conocimiento, y formulado con mayor precisión, como el sistema funcional de la ciencia" (Luhmann 1996:9).

En pleno sentido se trata de una tarea epistemológica, ya que si lo que se persigue es conocer la sociedad (y subsecuentemente a lo material, a lo vivo, a lo consciente), el primer paso tendría que ocuparse de las condiciones de la posibilidad del conocimiento, vale decir, la forma en que emerge la empresa científica. ${ }^{3}$ Al respecto, nos adentramos en un vasto terreno de investigación que ha ocupado un lugar privilegiado en el concierto de problemas tradicionales de la filosofía.

En la modernidad, la pregunta por las condiciones del conocimiento ha ocupado una gran cantidad de páginas en diversos ensayos y tratados, por lo que resulta evidente que una cuestión así tiene que anteceder cualquier tipo de investigación en pos de la verdad objetiva. En Kant tenemos un buen ejemplo (sin duda uno de los más importantes) de la moderna reflexión sobre el conocimiento en pleno desarrollo del lluminismo. ${ }^{4}$ Su contribución para establecer las condiciones de posibilidad de conocer "algo" mediante la "cognición del sujeto trascendental", abrió un amplio panorama sobre una controversia que continúa, bajo diversos tonos, hasta nuestros días: - cómo se conoce que se conoce, y más aún, cómo dicho conocimiento alcanza a ser verdadero-.

Casi todas las disciplinas en el concierto de la verdad han puesto su mirada en el tema. Desde la biología, la neurofísica, pasando por la sociología, la psicología y la lingüística, el problema (socio)epistemológico de la verdad ha ocupado un lugar considerable en los tratados producidos en el seno de cada disciplina. En este sentido, podemos preguntar por las condiciones físicas, biológicas, lingüísticas y sociológicas del conocimiento; sin embargo, la investigación que se lleve a cabo en torno a ello, siempre y cuando se proclame investigación sistémica, debe ser guiada siempre por una premisa autológica (Luhmann 1996:10) es decir, debe tener en cuenta las condiciones que de allí se desprendan para su propia actividad.

“En el contexto de una teoría de los sistemas sociales autopoiéticos, describimos la ciencia como un sistema funcional de la sociedad moderna que ha podido diferenciarse bajo condiciones históricas de marco social y convertirse en una unidad operativa propia, es decir, en condiciones para diferenciar lo verdadero de lo que no lo es" (Luhmann 1996:11).

Para desarrollar esta idea, en lo que sigue, nos concentraremos en ofrecer una exposición esquematizada que intentará mostrar cuáles son los instrumentos epistemológicos que esta sociedad genera debido a la forma de su autodiferenciación, para dar forma al sistema de la ciencia. Para lo cual nos extenderemos en los siguientes apartados: 1) conocimiento; 2) verdad; 3) la ciencia como sistema; 4) reducciones correctas y 5) ciencia y sociedad.

\footnotetext{
${ }^{2}$ Como referencia extra, el texto data de 1990. El deceso del autor ocurrió en 1998.

${ }^{3}$ En este enunciado se revela una buena parte del interés de nuestra investigación, ya que al emprender investigaciones sociológicas que sean plausibles, resulta conveniente hacer una revisión de aquel subsistema en el que se circunscribe la propia sociología, y la que de alguna forma la "faculta" epistémicamente.

${ }^{4}$ Véanse sus obras, Crítica a la Razón Pura y su Crítica a la Razón Práctica, así como también, el Ensayo, ¿Qué es la Ilustración?
} 


\section{Conocimiento}

\subsection{Designar, observar, describir}

En primer lugar, el conocimiento representa un elemento constituyente de la autopoiesis del sistema social. Su emergencia responde a un cúmulo de operaciones ligadas a una distinción que se sucede de forma recursiva en el marco de la comunicación social, compuesta por la secuencia del designar, el observar y el describir. Esta tercia de elementos, en conjunto genera un tipo especial de conjunto comunicativo que se designa como condensación:

"La cadena conceptual de designar, observar, describir, ya nos ha conducido hasta el punto en el que se tiene que hablar de condensación. Se produce así la fijación temporal que nos posibilita designar el conocimiento como una condensación de observaciones" (Luhmann 1996:94).

El despliegue de la unidad del conocimiento en estos tres momentos, permite observar un mecanismo similar al que se echa a andar mediante la observación. La designación señala el lado de la distinción con la que un observador podrá establecer el enlace de la siguiente comunicación, dejando el lado restante en estado de latencia o posibilidad (Rodríguez 207:XIV). Como resultado tenemos una observación proclive a establecer enlaces reduciendo complejidad y construyendo un posible entramado argumentativo. A partir de este proceso asequible a primera mano, podemos entonces saber, por ejemplo, "dónde se está cuando se dice estar en la Ciudad de México"; o "en Ciudad Universitaria"; "que el fuego quema"; o "quienes son nuestro padres". Más allá de estar aparejado a un reconocimiento de la realidad circundante, lo que se obtiene de este proceso es una observación con un rendimiento cognitivo capaz de lograr autopoiesis en el plano de la comunicación social.

No obstante, el conocimiento de algo como "algo", también desempeña un rol con cualidades, por decirlo de algún modo, adjetivantes, en donde posterior a la distinción de una cosa como tal, se es posible avanzar hacia su posible "descripción". Es en este momento en el que se logra establecer un conocimiento con una cuota mínima de estabilidad, que permitirá asegurar una comunicación con más elementos sobre algo en el mundo.

En su conjunto, el proceso del conocimiento en su presentación desglosada, arroja una textura suficientemente sólida para lograr una suerte de condensación, donde la solidez se puede apreciar en las consecuciones efectivas que esto tiene sobre funciones específicas en la sociedad. El hecho de saber que es medio día cuando el sol se postra sobre nosotros es una condensación cognitiva, así mismo cuando sé que terminaré en el hospital si me tiro por el séptimo piso del Instituto, por lo mismo que el suelo es sólido, por citar algún caso. Es decir, dichas condensaciones representan de alguna manera, la cuota suficiente de ingreso y membrecía a lo que se conoce como el mundo del sentido común; esto ya puede ser designado propiamente conocimiento.

La sedimentación del conocimiento requiere de tiempo. Ningún conocimiento puede llegar a ser tan efímero que no pueda ni siquiera reconocerse como memoria. Es por eso que también sólo el reconocimiento de que algo ya se sabía con anterioridad frente a algo que aún no se sabe, puede hacer surgir la distinción entre conocimiento y aprendizaje. De esta manera el conocimiento, así mismo, queda encajado en un esquema de distinción temporal.

El observador puede (y necesariamente debe) utilizar un esquema temporal y construir así una estabilidad. Puede constatar (pero únicamente en su momento) que el conocimiento se conocía ya antes y que probablemente se le conocerá después (Luhmann 1996:98).

Frente a esto, las estructuras cognitivas desempeñan un rol cardinal, ya que bajo la forma de expectativa de reconocer lo que se conoce, se podrá diferenciar lo que se conoce de lo que 
se está por conocer (bajo la forma de aprendizaje), manteniéndose lo último como un horizonte de expectativas a partir de vivencias sedimentadas.

Las estructuras erigidas, es decir, las expectativas alcanzadas (y las no alcanzadas también) condensan información generando conocimiento; listo para quien lo vuelva a poner en marcha al designar, observar y describir, asegurando así su reproducción circular.

\subsection{Estructuras y cognición}

Las estructuras facilitan la estabilidad de la información que se condensa, ya bien como memoria, ya bien como cognición. Para referirnos al concepto de estructura, ${ }^{5}$ decimos que su operatividad está sujeta únicamente al momento en el que son utilizadas, y posibilitan la autopoiesis en el momento en el que permiten enlazar futuras comunicaciones.

Al condensar la información, las estructuras reducen la arbitrariedad de lo que está por venir, ya que sus formas, digamos -sedimentadas- conducen las expectativas de las observaciones, reduciendo la contingencia y la improbabilidad de los enlaces comunicativos. De ahí que las estructuras funcionen operativamente, al enlazar comunicaciones de forma exitosa.

Como señala Luhmann: "Las estructuras también tienen una actualidad propia, sólo en el momento en el que son utilizadas. Reducen la arbitrariedad de lo que vendrá a continuación, como se dice también, posibilitan la redundancia y sirven para continuar la autopoiesis del sistema" (1996:100).

De este modo, la conformación de una estructura resulta un elemento de estabilidad (y también variabilidad) constitutivo para la emergencia del conocimiento.

\subsection{Realidad - mundo}

El conocimiento remite casi obligadamente a la realidad. Dejando de lado la posibilidad de un tipo especial de conocimiento de algo imaginario o etéreo (se sabe que se imagina o que se tuvo un sueño), queremos tratar el tema del conocimiento que remite a una realidad, clásicamente vinculado con la idea de lo existente, lo tangible, lo que está a la mano.

Bajo la perspectiva de la teoría de sistemas, la realidad adquiere una expresión distinta a las epistemologías de corte clásico, ${ }^{6}$ en cuanto a que pondera la multicitada tríada de diferenciaautorreferencia- autopoiesis, resultando conveniente tratar el concepto de realidad bajo una perspectiva operativa, a diferencia de una "esencial" o de carácter "óntico".

La realidad se lleva a cabo mediante la operación, por ende, todos los sistemas que observan son sistemas reales que establecen entre ellos relaciones "reales". Sólo así es posible entender el tipo de realidad con la que se trabaja desde esta teoría, la cual no considera más lo real como la "exterioridad" o las cosas "dadas en sí en el mundo que se encuentra fuera del sujeto", sino que en todo caso, considera su operatividad. El carácter operativo de la realidad resalta en cuanto se comprende como una observación que establece una diferencia diferenciando.

La realidad pertenece al orden de las cosas reales, es decir, está inserta en el mundo. Al respecto, más allá de entender el concepto como una suerte de receptáculo o contendor de todo lo que acontece, cual si fuera una gran almacén de la realidad, el concepto de mundo

\footnotetext{
${ }^{5}$ Las estructuras son condiciones que delimitan el ámbito de relación de las operaciones de un sistema: son las condiciones de la autopoiesis del sistema. El concepto de estructura indica por tanto la selección de las relaciones entre elementos que son admitidos en un sistema. Las estructuras también se refieren a las expectativas del sistema, como puntos de orientación. Véase. Luhmann 1998.

${ }^{6}$ Con esto, nos referimos sobre todo a la tradición iniciada por el racionalismo y el empirismo.
} 
despliega la unidad basada en la diferencia: “...hay que suponer que el mundo - sea lo que sea- tolera la diferenciación, y según la diferenciación que lo afecta, él estimula de distintas maneras las observaciones y descripciones así inducidas" (Luhmann 1996:71).

El mundo, entonces, es para todo sistema comunicativo lo que ellos tienen que presuponer para poder realizar las distinciones directrices que les permitan operar sus autopoiesis. Es en el mundo en donde se comete la "herida" que provoca el distinguir, quedando así partido, dividido, disuelto de toda unidad. Entonces, el conocimiento del mundo necesariamente conlleva una forma de observar autorreferencial, ya que de lo que se trata es de observar el modo en el que, precisamente, se puede observar; es volver sobre sí mismo.

El mundo es el punto ciego de su propia observación -aquello que no se puede observar cuando uno se ha decidido observar mediante una diferencia determinada-, por lo tanto, el mundo representa también el unmarked state de Spencer Brown.

Como se ve, la sed de principios ontológicos en el concepto de conocimiento, realidad y mundo quedan totalmente relegados, dando paso al trazo de una distinción constructiva hecha siempre por un observador.

\subsection{Conocimiento cotidiano/ conocimiento científico}

De esta manera, es prudente decir que el conocimiento posee una propiedad ubicua; estando siempre en uso en todos los ámbitos de la comunicación social. Esta situación por otro lado, genera que el mismo concepto pueda perderse en su generalidad, haciéndose poco claro. Para evitar esto, aquí ampliaremos el concepto del conocimiento utilizando la distinción entre conocimiento cotidiano y conocimiento científico. Es necesario ya introducir a la ciencia en esta distinción, ya que el conocimiento al que nos referiremos en este capítulo será uno de carácter científico.

El conocimiento es intrínseco a cualquier sistema funcional de la sociedad. Por lo mismo no le es, de ningún modo, particular al sistema de la ciencia: se requiere saber a cuánto asciende el tipo de cambio y los aranceles de cada país para exportar una mercancía, es necesario conocer el tipo de legislación vigente para iniciar cualquier proceso jurídico, siempre es bueno conocer al menos un poco a la persona con quien tendremos un encuentro amoroso, etcétera. Por ello, puede existir conocimiento incluso, sin sistema funcional de la ciencia.

La diferencia sustantiva del tratamiento cognitivo que efectúa la ciencia sobre el conocimiento meramente cotidiano, se concreta en cuanto a que ella deja tras de sí un conocimiento que sólo puede calificarse como evidente y familiar en la relación adecuada con objetos y fenómenos, vale decir, en cuanto a que ella logra generar conceptos y manejar éstos en un sentido teórico:

“Toda ciencia depende de conceptos que determinan qué se puede diferenciar de qué, qué se puede designar, observar, escribir, y quizá, explicar. Esto no significa de ninguna manera que todo el lenguaje de la ciencia consista exclusivamente en conceptos; pero sí que la ciencia se distingue de la comunicación social cotidiana únicamente en cuanto que utiliza conceptos y coordina su uso en su propio sentido (teórico)" (Luhmann 1996:94).

Por esta razón, el conocimiento puede ser comprendido en su uso científico (es decir, por un sistema) como una forma cognitivamente estilizada, que es el resultado del particular tratamiento de la información llevado a cabo por la ciencia.

La ciencia es ciencia en tanto que su aproximación al conocimiento se realiza de tal forma que problematiza relaciones triviales, a primera mano, tratando de esclarecer latencias que subyacen en fenómenos, objetos y cosas en el mundo observable, haciéndolo a través de 
métodos y teorías. Como tendremos oportunidad de ver a continuación, la ciencia es capaz de establecer su propia identidad frente al entorno a partir de la peculiar codificación entre verdad/no verdad, trazando límites y generando así auto- identidad.

\section{Verdad}

\subsection{Verdad como medio de comunicación simbólicamente generalizado}

El conocimiento es indispensable en la autopoiesis del sistema de la sociedad. Sin embargo, solamente en cuanto se preguntan por las condiciones en las que un conocimiento es verdadero, estaremos hablando de una comunicación que cae en los dominios de la ciencia. De aquí en adelante trataremos a la verdad como el medio operativo del sistema de la ciencia, justamente entendido como un medio de comunicación simbólicamente generalizado.

Si queremos tratar a la verdad como un medio de comunicación simbólicamente generalizado (en adelante MCSB), entonces debemos esclarecer este término. De manera general los MCSB, tienen menos que ver con un determinado medio de comunicación de masas como pueden ser la televisión, el radio o la Internet, que con una forma de reducción de la complejidad de la comunicación. Como tales, es importante hacer ver que no pueden ser ubicados como determinados objetos, o cosas. ${ }^{7}$

Si se pretende observar la verdad, entonces se tiene que recurrir necesariamente a una determinada observación de segundo orden, vale decir, observar a quien observa mediante el código verdadero/no verdadero, con el objeto de descubrir cómo es que se maneja ésta diferencia y cómo se encuentra en condición de producir así las siguientes diferencias.

Como medio, siguiendo la teoría de Fritz Heider (Luhmann 2007a) (Heider 1926), la verdad es capaz de acoplar formas que son estables en la medida en la que puedan reducir la contingencia a través, precisamente, de un determinado código. Estas formas adquieren una función similar a la de las estructuras en cuyo mecanismo de selección se encuentra condicionado el destino de las comunicaciones subsiguientes.

El medio realiza a la forma, y de regreso; la forma realiza al medio. ${ }^{8}$ Esto quiere decir que ambos representan a su vez la unidad de una diferencia. En esta relación, es importante hacer notar el papel que desempeña el código del medio, ya que es la bisagra de la relación entre medio y forma. En el caso de la verdad, "el código es una forma bilateral, con un lado interior (la verdad) y un lado exterior (la no verdad)" (Luhmann 1996:136), por lo tanto delimita el medio hacia el exterior; de esta forma se sabe que la verdad, y con esto, la ciencia, es específicamente la reproducción de la codificación verdaderol no verdadero y no otra cosa.

Como veremos más adelante, el código como diferenciación debe ser diferenciado bajo la dirección que imponga un determinado programa, el cual especifica bajo qué condiciones es correcto o incorrecto el determinar algo como verdadero o no verdadero. De ahí que bajo estos términos, "la verdad sea un medio codificado" (Luhmann 1996:137).

“El sustrato medial de la verdad no es, entonces, sino la capacidad de disolución de la ciencia vertida exitosamente en una forma, y que diseña un mundo que permite también otras combinaciones; por ejemplo un mundo matemático" (Ibíd.).

La correspondencia entre el medio y la forma que señalábamos se manifiesta ampliamente en el hecho del simbolismo que implica el medio de la verdad. Según Luhmann, la función de los

\footnotetext{
${ }^{7}$ Véase para un desarrollo del concepto: Luhmann 1998:159 y s.; Luhmann 2006a y Luhmann 2007b: 245-307.

${ }^{8}$ Manejamos la palabra realizar en el sentido de volver operativo.
} 
símbolos radica en invisibilizar la paradoja original de los medios autorreferentes: "el símbolo permite comprender la reentrada de una diferencia en lo diferenciado por ella" (Luhmann 1996:140). Es decir, el aspecto simbólico de los medios radica en su capacidad para evitar el bloqueo causado por la paradoja (que supondría que la comunicación no verdadera, ella misma puede ser una verdad) permitiendo la continuidad de una comunicación que es improbable. "Algo no planeado como afirmación verdadera puede convertirse en ella cuando una comunicación posterior, mediante una referencia refute o afirme la verdad" (Luhmann 1996:141).

El valor positivo del medio de la verdad (la verdad misma) genera, por así llamarlo, una capacidad de enlace en el sistema, en la medida en la que al volver la mirada a su operación, genera una comunicación auto-explicativa, que a su vez, permite aumentar el conocimiento y a su vez delimitarlo, por ello, se presenta como una cognición con un grado mayor de elaboración y organización (propiamente científica). Se trata también de un tipo especial de redundancia informativa, que incrementa la probabilidad de producir otras informaciones, reduciendo con ello el factor de la sorpresa, o en un caso extremo, un eventual bloqueo.

El medio verdad simboliza con su valor positivo la capacidad de enlace del conocimiento. “Presenta una sincronización aparentemente lograda desde lejos y enlazado a ésta, permite, entonces, los condicionamientos (programas, es decir, las teorías y los métodos) de la utilización de este símbolo" (Luhmann 1996:148).

Por esta razón, la verdad puede reformularse como la capacidad de enlace simbolizada, que permite actualizar formas en su propio medio codificado. En el caso de las matemáticas, por ejemplo, su capacidad adquirida no radica en haber logrado una adecuación del tipo ideal con el universo; pensarlo así, según Luhmann, conduciría a plantear un universo - que es matemático-. Más bien, lo que aquí se propone es hacer notar la "cualidad autorreferencial del medio verdad", ya que lo que se logra enlazar como verdad, únicamente se refiere a una comunicación codificada, simbolizada y generalizada que permite la reproducción autopoiética, seleccionando aquellas comunicaciones que mejor se han adaptado a la selección impuesta por programas, arrojando así, una verdad científica: un verdad matemática (forma) que es válida sólo para el sistema científico- matemático (medio). Tener en cuenta lo anterior es muy importante, ya que deriva en comprender la verdad como una redundancia interna a los propios sistemas.

El afán de la verdad conduce también al error, por ello, aquí también juega un papel importante. El error es el correlato codificado de la verdad, y a su vez, también logra realizar una capacidad de enlace con subsiguientes comunicaciones, en tanto que garantía de abrir una posibilidad; por ello, el error se puede expresar también como conocimiento latente.

La verdad designa lo que es; la no verdad, al colocar esto "entre paréntesis", hace surgir la reflexión sobre esta afirmación (Luhmann 1996:149). De esa manera, es en el lado negativo en donde se realiza la diferencia en la diferencia, por lo tanto se presenta un re-entrada. Lo no verdadero, se aplica a sí mismo una distinción de verdadero/no verdadero para saberse a sí mismo algo no verdadero. Sólo así se puede explicar el vericueto lógico que plantea el que una oración que dice "esto no es verdadero" ella misma pueda ser una oración "verdadera".

Para ello hemos abierto un subtítulo aparte para retomar la controversia sobre el tema de la reflexión. Aquí sólo nos toca resumir señalando que la verdad se encuentra de tal manera generalizada como un medio de comunicación en el sentido, que es capaz de clausurar formas en el entramado comunicativo de la sociedad. Como la unidad de una diferencia, la verdad se despliega mediante la codificación en torno a la fórmula binaria denominada verdadero/no verdadero. Sólo a través de este código, la verdad puede reducir la complejidad y señalar lo que pertenece a un enunciado verdadero en el presente, y a lo que posiblemente se designe bajo esa misma etiqueta en el futuro. Las formas creadas por la verdad 
(enunciados, teorías, métodos, publicaciones, descubrimientos, tratados, etcétera), son formas que funcionan internamente en los sistemas que por medio de este MCSG reproducen información, en este caso: el sistema de la ciencia.

De esta forma, la verdad asegura la capacidad de enlace en el sistema de la ciencia. Como MCSG pone a disposición un tratamiento comunicativo que posibilita la clausura operativa y la capacidad de enlace del sistema de la ciencia, bajo el código verdadero/no verdadero. En otras palabras, le confiere identidad a la ciencia, señalando también sus límites propios.

Con lo dicho hasta ahora, debemos hacer una acotación. Los MCSG no pueden ser entendidos como una causa de la verdad, mucho menos como un logro de la misma. Los medios surgen en la práctica comunicativa misma, acoplando comunicaciones de manera un tanto más rígida en momentos más significativos. Luhmann lo explica del siguiente modo: “...toda comunicación específica de un medio tiene que referirse siempre a otras comunicaciones en el mismo medio para establecer el propio medio. La diferencia medio/ forma se produce al presuponerla y al hacer uso de ella" (Luhmann 1996:176).

\subsection{Reflexión}

La verdad como diferencia es la unidad de la verdad y de la no verdad. También podríamos decir, la verdad posee una forma que se desdobla como autorreferencia y heterorreferencia. Si habíamos dicho que la primera distinción le confiere capacidad de enlace a la verdad, como una condensación o redundancia informativa, entonces el lado opuesto, se encarga de hacer un alto y confirmar dicha selección; también podríamos decir: la reflexión sobre la verdad.

“Esta designación (observación, descripción) del sistema por el propio sistema es la que llamaremos reflexión, y para que quede clara la diferencia para una simple producción de la unidad del sistema (vista por un observador externo) en el caso de la reflexión no hablaremos de unidad, sino de identidad" (Luhmann 1996:344).

Comprendiendo a la verdad como forma desdoblada, la reflexión corresponde al lado de la distinción "no verdadero", por lo que también se dice que pertenece al lado negativo del código.

La reflexión aquí debe ser entendida como una comunicación sobre la comunicación; con respecto a la redundancia, que se refiere a la comunicación como continuación de la comunicación. Entonces oponemos "condensación" (redundancia) a la "confirmación" (reflexión), en la misma forma en la que se encuentra opuesto el mismo código (verdad/no verdad).

Lo no verdadero, hace surgir un problema que impide momentáneamente la capacidad de producir comunicaciones verdaderas. Aunque siempre sea posible argumentar diciendo que "es verdad que esto no es verdad" teniendo con ello una paradoja que bloquearía cualquier intento de consumar una verdad "verdadera". Ante esto surge la necesidad de desparadojizar la referencia, es decir, de utilizar una forma asimétrica que asegure la autopoiesis del sistema y que evite un eventual "cortocircuito".

Precisamente, en el proceso de la reflexión el sistema evita el bloqueo paradójico utilizando para ello al tiempo: "Sólo mediante un entramado temporal y social se resuelven tanto los problemas del inicio, como los problemas de la paradoja de la forma, que puede distinguirse y puede no distinguirse a sí misma" (Luhmann 1996:59). El tiempo posibilita aquel crossing que es indispensable para conformar la unidad de la distinción, produciendo con ello la información de la unidad del propio sistema (como identidad), vale decir, una observación de la operación del sistema en el sistema. El tiempo no anula la paradoja, sino que la hace 
manejable, ya que al establecer el cruce entre uno y otro lado de la forma, rompe la simultaneidad y echa a andar la distinción en una secuencia de antes y después. El que sea verdadero que algo no sea verdadero, sólo se puede sostener en un antes y un después, indicando el lado de la distinción no verdadera, para inmediatamente cruzar hacia el lado verdadero. Este cruce es operativo en cuanto a que considera a la primera distinción (la cual es ni más ni menos la distinción directriz del propio código) como una comunicación precedente más, a la cual hay que aplicarle también el mismo código, pero volvemos a insistir, únicamente en un antes y después.

De este modo, decimos que en la reflexión del medio de la verdad en el sistema de la ciencia se opera una re-entry de la distinción verdadero/no verdadero en lo que ésta misma distingue, y esto a través de una operación ulterior. Esta situación tiene como consecuencia que el sistema adquiera informaciones sobre sí mismo, es decir, genere observaciones especiales que informan al sistema sobre el sistema, o lo que es lo mismo, informan a la distinción verdadero/no verdadero sobre la distinción verdadero/no verdadero. Ante esto se puede preguntar ¿a qué clase de observación nos estamos refiriendo para llevar a cabo la reflexión sobre la operación del sistema?

Al hablar de la observación - no de los observadores- sino de las propias observaciones, el sistema gana una distancia sobre sí mismo, podríamos decir una posición abstracta, que sin salirse de sus propios límites puede reflexionar sobre su rumbo. Esta distancia tiene que ver con un subproducto de la ciencia, que en este caso puede ser una teoría, que tiene como objeto distinguir las condiciones en las que su creadora puede, precisamente, crearla a ella misma (distinction is perfect continence, diría aquí Spencer Brown). Nos estamos refiriendo sin duda a la teoría del conocimiento o epistemología.

Ambas descripciones (reducciones correctas también podríamos decir), como tales, son productos de la ciencia. Sin embrago, éstas se presentan de un modo especial debido a su composición netamente reflexiva. La teoría de la verdad sobre la verdad, es decir de lo que hay de ciencia en la ciencia, representa un problema extrañamente autorreferencial, en el que resulta indispensable instalarse en un tercer nivel de observación: "el problema de la reflexión, ya no es la unidad de la diferencia entre el conocimiento y el objeto; sino que con respecto a la unidad del sistema, se trata del entramado de las relaciones de observación y de los límites sistémicos continuamente producidos; es decir, se trata de autopoiesis. El resultado de esta reflexión puede designarse como constructivismo" (Luhmann 1996:362).

El constructivismo entonces, se muestra como la teoría reflexiva de la ciencia con los rendimientos más óptimos para dar cuenta de lo que implica el razonar sistémico: "Se puede hablar de constructivismo siempre y cuando se pretenda designar una autodescripción del sistema científico, que ve el problema en cómo llegar de una operación a otra, continuando así la autopoiesis del sistema en un entorno al que no se puede conocer, sino únicamente construir" (Luhmann 1996:366). Esta observación reflexiona sobre las condiciones bajo las cuales, por ejemplo, se trata de explicar teóricamente la plausibilidad de un programa de conocimiento guiado por la diferencia, la autorreferencia y la cerradura operacional.

La reflexión del sistema, representada por la teoría del constructivismo procesa la idea de la pérdida de la unidad que se presumía ontológica de la realidad y del mundo. En su lugar arroja una propuesta cargada hacia la policontextualidad (Gothard Günther) y las realidades dependientes de la observación, por lo que su concepción de algo como "algo", debe ser menos trascendental que autológica, menos relacional que operativa y también, menos teleológica que contingente.

El sistema de la ciencia, a través del código del MCSG de la verdad, alcanza a reflejarse a sí mismo, es decir, a colocarse como su propio objeto, a través del lado negativo de la distinción. Esto es lo que se ha llamado reflexión. De esta manera, la reflexión posibilita la emergencia de una observación al interior de su observación, que se encarga de analizar sus 
condiciones de observación; de ahí surge un determinado programa epistemológico. Para nuestro caso, como dijimos, se trata del constructivismo.

A partir de esto, y considerando el paquete teórico del que está dotada la teoría de sistemas y su reflexión constructivista, el concepto de reflexión permite dar cuenta del carácter autológico de todo sistema que se observa, esto es, al comprender los sistemas como unidades autopoieticas y operativamente cerradas que producen ellas mismas su unidad, la reflexión misma se convierte en una operación de tales sistemas, es decir, se trata también una autodescripción, con lo que, nuevamente, la idea de la realidad "tal y como es", artificial y absoluta, externa para quien observa, queda fuera de servicio para la ciencia y su descripción.

\subsection{Crédito y reputación}

Todos los medios de comunicación simbólicamente generalizados están basados en parte en el crédito (Luhmann 1996:171). El crédito consiste en observar las expectativas de las demás observaciones involucradas en la obtención de la verdad. De ahí que en el crédito exista una relación de doble contingencia.

El crédito necesita echar mano de la confianza en el medio de la verdad. Precisa el mutuo acoplamiento de expectativas entre terceros, las cuales tienen que estar dirigidas de forma coherente hacia los supuestos que así quedan explícitos en un determinado medio: en un encuentro de nanotecnología no se puede esperar que se tematice en una conferencia sobre la corbata y el gusto personal del expositor (por más que todo sea tematizable). Por ello, el crédito se convierte, para expresarlo de algún modo, en una moneda de cuenta corriente para jugar en el medio de la verdad de manera coordinada.

El crédito depende fundamentalmente de la reputación de quienes reproducen una comunicación con intenciones de ser verdadera. Es la reputación quien construye los cimientos del crédito de una afirmación que se presume verdadera.

A partir de esto se puede preguntar ¿por qué razón sería necesario consultar a una figura de autoridad, a un depositario de la verdad, a un autor de renombre para convalidar la comunicación que se ha producido al interior de la ciencia? Esto es el problema del denominado observador sobrecargado, que se desprende de lograr estabilidad ante la vertiginosidad de las transformaciones del conocimiento científico. De esta manera, la reputación se presenta como un factor simbólico que permite un tipo orientación abreviada.

"Por lo mismo, el sistema tiene que poner a disposición modelos para reducir la arbitrariedad de selección de temas, de la lectura, de las citas, y de las formulaciones, y precisamente eso sucede en la ciencia mediante el establecimiento de la reputación" (Luhmann 1996:177).

Tal importancia adquiere la reputación en el medio de la verdad, que su efectividad causal tiene que ser entendida como un código lateral o secundario que acompaña palmo a palmo a la codificación verdadero/no verdadero: ella realiza un acoplamiento estructural con el este código. De esta forma, la reputación se "binariza", presentándose como la unidad de la diferencia entre lo que se podría designar como logro de novedad/estancamiento. ${ }^{9} \mathrm{Si}$ se observa con detalle, muchas instituciones científicas (universidades, institutos, centros, programas, etcétera) toman muy en cuenta esta codificación, tan sólo baste mirar el interés por los nombres de quienes publican y cada cuándo lo hacen. En numerosos casos, firmar una publicación con un determinado nombre y no otro o bajo el auspicio de tal o cual grupo,

\footnotetext{
${ }^{9}$ Hemos presentado esta distinción deliberadamente a partir de una interpretación del texto original que aquí reproducimos: "Del lado positivo (del código de la reputación), designa el logro de la comunicación primicia del conocimiento nuevo, y del lado negativo, la ausencia de tal logro". (Luhmann 1996:179).
} 
puede asegurar digamos, por default, que la aceptación en la comunidad será satisfactoria o no. Aunque por otro lado, precisamente en función de lo anterior, esta observación sobrecargada, inflada por causa de su misma agencia de reputación, resulta ser un blanco constante de críticas y comentario; en razón de su importancia se deduce su vulnerabilidad. Los cocteles, invitaciones, laudatios, homenajes, premios y demás "pasarelas académicas" no hacen sino demostrar el peso y la vigencia de este código, el cual por ejemplo, bajo circunstancias donde los acoplamientos intersitémicos son elevados, como hacia la política, la economía, o incluso también hacia la religión, este código puede tener igual o mayor protagonismo que el código verdadero/ no verdadero.

Como sea, la reputación es un factor indispensable de la realización del medio de la verdad, y por lo tanto del sistema científico mismo. Para enfatizar, decimos que su principal función radica en orientar la selección de las comunicaciones científicas que se tienen que tomar en cuenta al interior del sistema, sin embrago, y para diferenciarlos de los programas, que veremos más adelante, su carácter de código resalta el hecho de que la reputación se encuentra en todas partes en la verdad, vale decir, que todo el medio y no sólo una parte de la investigación está estructurado así.

Resumiendo: "Se trata, en otras palabras, de un proceso autorreferencial de la condensación de atención, construido y reforzado a través de estrecheces en el tiempo disponible y en las oportunidades para publicar" (Luhmann 1996:181).

Crédito y reputación se corresponden mutuamente para servir de complemento a la explicación sistémica del código de la verdad y la comunicación científica.

\subsection{Riesgo como hipótesis}

Dado que la sociedad, como hemos visto, consiste de comunicaciones y solamente comunicaciones, no existen los contactos con el entorno en el nivel de sus operaciones. Sin embargo, esto para nada anula la posibilidad de que los sistemas sean capaces de comunicar sobre sí mismos, pero también sobre el entorno.

Ante una cada vez mayor complejidad del mundo social, como resultado de la inconmensurabilidad de comunicaciones, funciones y estructuras ejecutándose en su interior, los contactos punto por punto de los sistemas con su entorno no pueden sino parecer una gran entelequia. Esto, sin embargo, no invalida el hecho que el entorno siga (y seguirá) irritando al sistema, aumentando con ello la susceptibilidad y sensibilidad de los sistemas.

En función de lo anterior, surge el concepto de riesgo, al cual nos referimos al observar las irritaciones (potenciales y manifiestas) que el sistema proyecta sobre su entorno.

Pensar en riesgo es pensar en los daños que surgirán o no surgirán como consecuencia de la acción u omisión propia, mientras que pensar en peligros se remite a los daños que aparecerán o no sin la intervención propia (por decir, inminentes) (Luhmann 2006b). ${ }^{10}$ Para ser asignados, los riesgos tienen que ser visibles, es decir, ubicables en la distinción sistema/entorno. Luhmann también agrega: "Sólo se puede hablar de riesgo, sin importar cómo se entienda el término, cuando se presupone que quien percibe un riesgo y posiblemente se le enfrenta, ejecuta ciertas distinciones, por ejemplo la distinción entre resultados buenos y malos, ventajas y desventajas, utilidades y perdidas, así como la distinción entre probabilidad e improbabilidad de que ocurran estos resultados" (y no otros). (Luhmann 1996:279). En el medio de la verdad, el riesgo se presenta en la relación que se establece entre la formulación de una teoría y su eventual comprobación, o negación en la realidad. De ahí que también el riesgo se encuentra relacionado estrechamente con la idea de la confianza.

\footnotetext{
${ }^{10}$ Especialmente el Capítulo 1: "El concepto de riesgo".
} 
El riesgo trabaja con incertidumbre; siempre cabe la posibilidad de que nuestros enunciados de verdad sean falibles ante una comprobación empírica. Pero ¡cuidado! por ello no se debe regresar a la idea de la inmanencia ontológica de lo real; el riesgo es precisamente riesgo y no peligro, porque la cuota de incertidumbre, inseguridad y desconfianza es un producto de lo que ella misma se ha provisto, es decir, por lo que el riesgo también es autología implicada.

La ciencia trabaja con riesgos, vale decir, con inseguridades lo suficientemente manejables para no caer tampoco en un bucle de relatividad y de escepticismo totales. Sus decisiones sólo pueden tomarse en este ambiente, aunque sin este ambiente la ciencia no podría realizar su autopoiesis.

“El riesgo propio de las comunicaciones científicas se designa sobre todo con el término hipótesis. Con este término, la ciencia reacciona en primer lugar ante la circunstancia de que está ocupada con la adquisición de nuevos conocimientos y no sólo con el recuerdo de lo que ya se sabe" (Luhmann 1996:183).

El concepto de hipótesis encubre el hecho de que la ciencia pueda trabajar en medio de un ambiente repleto de inseguridades, las cuales tendrán que ser tematizadas en términos propios. Las expectativas puestas en la fuerza explicativa de las hipótesis no radican en su correcta adecuación con el mundo (podemos pensar también en figuras clásicas como la perfecta "adecuación entre la palabra y la cosa", por ejemplo) sino, más bien al estado mismo de las investigaciones al interior de la ciencia. Por eso mismo, puede decirse que "el intercambio de teoría y verdades no está determinado por cómo va el mundo, sino por cómo va la investigación" (Ibíd.).

Ante una cuota tan elevada de incertidumbre, salta a la vista la pregunta por las condiciones en las que la ciencia puede mostrarse exitosa, o en las que ella puede resolver los problemas al interior de la sociedad. Precisamente la ciencia a través del acoplamiento con la tecnología trata de cubrir esta necesidad autoproducida. Sin embargo, la tecnología no puede hacer de lado, ni mucho menos anular el riesgo, ya que al tapar un hueco de problemas, inminentemente quedarán otros sin atender. Además, el riesgo siempre acompaña los procesos de aplicación científica en el ámbito social, ya que siempre serán inconmensurables las consecuencias de algún implemento o manipulación, principalmente en razón de la propia complejidad. ${ }^{11}$

“Esto no significa que impera la pura arbitrariedad; pero sí que la domesticación de de lo improbable depende de condiciones propias del sistema que a su vez sólo pueden ser cambiadas mediante operaciones propias del sistema, y eso únicamente si permite explicaciones (reformulaciones) de un mayor alcance y capacidad de enlace" (Luhmann 1996:184).

Así, en el estado actual de la diferenciación por funciones de los sistemas, no existe un ámbito especial de decisión, al menos unívoco y total dotado de una racionalidad superior, capaz de domesticar la complejidad (y ni qué decir del Estado) (Mascareño 2004). La ciencia entonces, sólo puede limitar las consecuencias no esperadas de sus productos con los controles impuestos por el entorno, los cuales, por otro lado, nunca alcanzarán a ser suficientemente coactivos (nuevamente, en razón de la sombra de la complejidad).

\footnotetext{
${ }^{11}$ Véase para esta idea tan sólo los problemas con los que se enfrentan las reformas educativas para poder armonizar la igualdad de oportunidades y la selección sobre capacidades, y con ello poder realizar sus objetivos punto por punto en el proceso educativo. Corsi 2002.
} 
En suma, el riesgo como hipótesis, marca el carácter contingente del sistema de la ciencia, haciéndonos recordar al viejo Descartes y la afirmación que dictaba que el espíritu científico consiste en dudar y sólo esta condición promueve su continuidad.

\subsection{Jerarquía}

En una teoría que tiene como basamento la diferencia, el esfuerzo por hallar un centro o una instancia rectora que administre la complejidad y la "domestique", presentándola como unidad, es dejado de lado drásticamente. En su lugar, emergen relaciones y operaciones que enlazan comunicaciones, siempre de forma policontextual.

Como dijimos, si la verdad posee capacidad de enlace, esta ocurre en condiciones netamente improbables y no en un ambiente de absoluta certeza. Entonces, con la probabilidad limitada, se puede decir que la verdad pertenece a un ámbito pleno de inseguridad, de ahí que su posesión por parte de algún sistema observador, no le garantiza aumentar su ascenso jerárquico en la sociedad.

Quien posee verdad, no la puede intercambiar como un título de poder o de jerarquía, ya que el mundo, sin un centro o cabeza, no puede reconocer una sola y menos aún, definitiva. La verdad, sólo es efectiva hacia los mismos términos del sistema en la que fue planteada.

La jerarquía es un concepto que vino aparejado con la estratificación por funciones. Éste cumplía con la configuración de las expectativas acordes a las estructuras formadas bajo las distinciones asimétricas, como la de centro/periferia; villano/forastero rey/súbdito, fiel/ pagano, etcétera. De tal forma que la jerarquía se presentaba como una "redundancia de expectativas" (Luhmann 1998:272), que al fijar sólo aquellas que le fueran asimilables y controlables, podía generar una estructura rígida, poco sensible a los cambios y la contingencia.

Sólo a partir de la transformación histórico- evolutiva de la configuración de estructuras, - en donde la diferenciación por funciones ya era la diferenciación que más óptimamente podía lidiar con la complejidad del sistema social, presentándose como un "primado"-, la conducción jerárquica tuvo que retroceder paulatinamente y transformarse en una distinción funcional, por ende, intercambiable y sustituible.

No obstante, es adecuado señalar que con la diferenciación por funciones el ordenamiento jerárquico no desaparece (la diferencia riqueza/pobreza, centro/periferia o educado/no educado sigue teniendo una alta relevancia social) sino que queda subordinado a este primado, perdiendo su nivel rector. En el caso de la ciencia, bajo el nivel de la reputación, el crédito y el prestigio, esta función jerárquica (de una naturaleza distinta respecto al pasado), tiene presencia y contribuye a la reproducción social de la verdad, pero, y es importante recalcarlo, únicamente como elemento y no como primado funcional.

Como lo hemos visto, el concepto de verdad aquí descrito ya no tiene que ver con una determinada "inmanencia" de los objetos reales, ni mucho menos con una "adecuación racional" entre el concepto y la cosa en sí, tal y como lo pensó la semántica de la Europa de tricornio y peluquín. Tampoco con un determinado consenso comunicativo racional con pretensiones de validez, como lo ha pensado Habermas (1997), o como un cierre de filas en torno a un paradigma, como lo planteó Kuhn (2005). Más bien, lo que debemos manejar claramente como verdad en su aproximación más abstracta se refiere a "una designación desarrollada en la comunicación para fines de la comunicación" (Luhmann 2007b:130) al interior de la misma. La verdad, para repetirlo, es un medio de comunicación simbólicamente generalizado, operativamente indispensable - únicamente- para la autopoiesis del sistema de la ciencia. 


\section{La ciencia como sistema social}

Pasaremos a explicar el siguiente apartado en forma de esquema. Vamos a desarrollar por partes los elementos que hacen de la ciencia un sistema social, en algo que hemos definido como las condiciones de "sistemidad" de la ciencia. Recordemos que los límites del sistema equivalen a su distinción, vale decir, a su identidad como sistema, en donde la diferencia, la autorreferencia y la autopoiesis dan cuenta de su autoconstitución.

¿Bajo qué razonamientos teóricos es posible entender a la ciencia como un sistema social? Para responder esto desarrollaremos los siguientes conceptos: autopoiesis, clausura operativa, autonomía y estructuralidad. Precisamente, de la autopoiesis del sistema de la ciencia daremos cuenta a continuación.

\subsection{Autopoiesis}

La ciencia es un fenómeno que acontece en la sociedad. Por esta razón, la idea de seguir estudiándola a la luz de una teoría sociológica no puede sino ampliarse y discutirse. Su emergencia supone un estadio socio- evolutivo que, según una periodización basada en las formas de diferenciación de los sistemas, corresponde a la diferenciación por funciones. Si bien la verdad ha existido sin algo así como la ciencia, a lo largo de la historia del hombre, ${ }^{12}$ sólo bajo su hospedaje en la ciencia como sistema funcionalmente diferenciado, la verdad ha ganado en complejidad y contingencia.

Una observación teórica de segundo orden, como la que hasta ahora hemos tratado de hacer, razona que la verdad reacciona al marco operativo de la diferenciación funcional de tal manera que queda constituida bajo la forma de un código que impera sobre el sistema de la ciencia.

Un sistema se genera a partir de un determinado código que le permite seleccionar los elementos necesarios para asegurar su continuidad, de ahí que más allá de ser un conjunto estable, y ordenado por un entorno, un sistema es dinámico y depende únicamente de la selección de sus operaciones.

En ese sentido, todo sistema está en condiciones de producir los elementos necesarios para ser sistema y para seguir siéndolo a continuación. Precisamente en esto consiste la autopoiesis; la forma en la que un sistema produce y reproduce por sí mismo los elementos que lo constituyen. Entonces, si se desea organizar teóricamente a la ciencia como sistema, será necesario observar su autopoiesis.

"La autopoiesis del sistema no requiere de otra cosa que de la continuación de la comunicación acerca de la verdad y falsedad; es decir, de la continuación de la comunicación en este medio simbólicamente generalizado" (Luhmann 1996:205).

Como el mismo Luhmann explica a continuación, para que esto suceda, en primer lugar se tienen que conformar las correspondientes expectativas comunicativas para quedar de tal manera organizadas como estructuras. Una irritación del medio puede alterar el funcionamiento del sistema a nivel estructural, sin embargo, en el nivel operativo, el sistema sólo reacciona a lo que puede observar, es decir, hacia aquella operación que procesa y que le confiere identidad: comunicación sobre la verdad o la falsedad, y nada más. Por esta razón, el concepto de autopoiesis constituye la condición mínima de la diferenciación de la ciencia.

\footnotetext{
${ }^{12}$ Por poner sólo un ejemplo, véase la idea sobre la verdad y la función del testigo en el mundo helénico en el estudio de La verdad y las formas jurídicas de Michel Foucault, así como también, la pregunta por el conocimiento en los diálogos Teeteto y Menón de Platón.
} 
La autopoiesis es un principio ateleológico y la ciencia sólo puede generar verdades y falsedades cuando, por lo menos, continúa conservándose y reproduciéndose en la sociedad como un sistema autopoiético.

Si la ciencia se reproduce autopoiéticamente como un sistema, entonces también lo hace basándose en una reducción que no hace sino construir una complejidad para el sistema mismo. Complejidad que es construida, no obstante, tomando en cuenta las irritaciones que provienen del entorno. Este ir y venir de información sobre el mundo (y sobre el propio sistema) se lleva a cabo a través del carácter cerrado del sistema.

Cerradura aquí nuevamente quiere decir, que el sistema sólo es susceptible a lo que él mismo produce, en este caso; a la comunicación sobre la verdad y la falsead. Esto sin embargo, no presupone una total indiferencia al entorno o un drástico hermetismo, más bien su observación es un logro propio del sistema.

"Aunque los ruidos provengan de fuera, constituye un logro propio del sistema lo que pueda entenderse de manera clara y distinta acerca de ellos, lo mismo que el modo en el que de ellos puede obtenerse informaciones y el tipo de expectativas que preparadas de esta 0 aquella forma, confirman o desilusionan" (Luhmann 1996:207).

En función de lo anterior, podemos agregar que la autopoiesis clausura al sistema, cerrándolo operativamente y con ello, generando autonomía, un principio más de sistemidad de la ciencia.

\subsection{Clausura operativa y autonomía}

La clausura (o cerradura) operativa del sistema de la ciencia permite mostrar qué es lo que este sistema produce y ejecuta de modo particular a los observadores teóricos (observadores de segundo orden) interesados en estudiar al sistema.

Mediante el establecimiento de fronteras, es decir, de límites que hacen que los sistemas no se disuelvan en el entorno circundante, la ciencia puede ubicarse como un corpus de discusión científica (en este caso para la sociología). Para nuestros fines, esto significa el identificar el código específico verdadero/no verdadero, así como también el código secundario de novedad/ estancamiento.

"La referencia verdad/falsedad hace posible la relación recursiva de las comunicaciones entre sí, por lo que se determina de operación en operación (...) Si en lugar de esto lo que nos preocupa es la diferencia entre bueno y malo o entre útil y dañino, la comunicación no se efectúa en el sistema de la ciencia" (Luhmann 1996:223). ${ }^{13}$

Todas las operaciones para las que esta diferencia es válida serán operaciones del sistema de la ciencia, quedando relegado todo lo demás. Entonces la tarea de la investigación consiste (y no sólo para el caso del sistema de la ciencia) en encontrar el código específico que se encuentre en coordinación con un determinado sistema. De esta manera, decimos que el sistema al establecer el código que hace posible su autopoiesis, efectúa una cerradura operativa, que enmarca sus propios límites y su propia identidad. Veamos.

La cerradura operativa sólo puede alcanzarse mediante una codificación binaria. Esta codificación se presenta como un sustrato medial que sólo despliega unidad mediante diferencia. Por esta razón, también se puede decir que la cerradura de un sistema codificado reproduce de alguna manera, la cerradura del mundo. "El código define un mundo y al mismo

\footnotetext{
${ }^{13}$ Es así como la ciencia se descubre en la circunstancia especial de ser ella misma un objeto de estudio de la propia ciencia. (La acotación es mía).
} 
tiempo define operaciones que a su vez determinan un sistema que se delimita en el mundo para poderlo observar" (Luhmann 1996:224).

Cerradura operativa implica selección; el sistema se torna más selectivo en el momento que identifica sólo las operaciones que aseguran su autopoiesis con una mayor nitidez (el equivalente a saber qué es lo efectivamente se hace). De esta manera, el sistema puede observar que se observa a otros sistemas y a sí mismo, mediante, por ejemplo, la distinción operativa de verdadero/falso. Sin esta condición los sistemas bloquearían su capacidad de observar, disolviéndose en una completa dispersión. Más adelante veremos cómo un sistema, mediante programas (métodos y teorías), logra estructurar tales selecciones.

Cerradura, por otra parte, también implica apertura. El concepto no refiere bloqueo o hermetismo por el cual el sistema no reconozca un medio, al contrario, el término clausura (en inglés closure en lugar de closedness) implica que el sistema al cerrarse "no excluye en forma alguna su apertura, sino que constituye más bien una condición necesaria para que el sistema pueda entrar en contacto con un entorno complejo y distante" (Luhmann 1996:218). ${ }^{14}$

En el tema de la clausura nos encontramos con un razonamiento que se encuentra íntimamente ligado a la cibernética en cuanto al principio de la autonomía, ahí cuando esta señala que los sistemas que computan obtienen su autonomía al computar sus propios límites. ${ }^{15}$ Por esta razón, el sistema también reconoce autonomía respecto del entorno, cuando y sólo cuando se reconoce como operando bajo un determinado código y no otro distinto: la ciencia puede producir una cura efectiva contra el cáncer, lo cual disminuiría la tasa de mortandad adulta y aumentaría la población en edad de trabajar, elevando la productividad de un país, causando una mayor demanda en el consumo adulto; cualquiera de estas cosas tendría muy diversas lecturas y consecuencias, sin embrago, se constituirían como tema científico únicamente, en cuanto a que ellas fuesen vistas a partir del código verdadero/no verdadero. Ahí radica un importante rasgo de autonomía sistémica, la cual está aparejada con la clausura operativa.

La autonomía provoca que las irritaciones de otros sistemas no afecten para nada la operación del código del sistema, en cambio, lo que sí sucede es que se aumenta la complejidad por lo que el sistema se vuelve cada vez más susceptible a factores ajenos, empero, sin trastocar su unidad operativa ni su autonomía: el hecho de que el buen término de una investigación dependa del financiamiento otorgado por una empresa interesada en los beneficios de los resultados, no cambia para nada el que la investigación, si es científica, tendrá que basarse en la codificación que ya conocemos; cualquier otra orientación de algún otro código, arrojaría otra actividad.

Entonces, a través (pero no exclusivamente) de la clausura operativa y la subsecuente autonomía, los sistemas delimitan más claramente sus bordes y operan en la sociedad sabiendo qué observan y cómo es que observan. Por ello, en la configuración de un sistema, este par de conceptos desempeñan una función diríamos de demarcación, para ubicar mejor los límites sistémicos.

\subsection{Estructuralidad}

Para finalizar este apartado, se hará mención de un concepto que designa un conjunto de principios mediante los cuales los sistemas se encuentran estructurados.

\footnotetext{
${ }^{14}$ Esta idea también la podemos encontrar en Edgar Morin, en el tercer volumen de su estudio El Método. Morin 1986.

${ }^{15}$ Véase: G. PASK. 1981. "Development in Conversation Theory: Actual and Potential Applications". En: Applied Systems and Cybernetics III, Lasker, G.E. (ed.), N.Y.: Pergamon Press, p. 1326-1338. Citado en: Luhmann 1996.
} 
La estructuralidad aparece como otra condición más de sistemidad. Su funcionamiento está directamente relacionado con los principios de la autopoiesis, clausura operativa y autonomía que señalamos más arriba, además de otros elementos como la observación, la operación y el sentido.

Los sistemas presuponen estructuras formadas para seguir operando. Más aún, como sistemas recursivos, además de poseer una sensibilidad ante los sucesos del entorno, sobretodo, poseen una gran sensibilidad frente a los efectos de su propia operación. De este modo, los sistemas recursivos operan a partir de una determinación estructural.

"La ciencia recursiva constituye, como todo sistema, un sistema estructuralmente determinado: se encuentra siempre únicamente en el estado que ha alcanzado gracias a sus propias operaciones" (Luhmann 1996:201).

Aquí, la determinación debe ser entendida como la sucesión y modificación de las estructuras que depende precisamente de las mismas estructuras. Por otro lado, la determinación estructural también está fincada en el nivel de las expectativas de los observadores, por lo tanto, se habla de una estabilización de la estructura, cuando una observación (propia o extraña) puede inferir aquellas comunicaciones que serán asimiladas por el sistema como enlace, o como simple ruido: el sistema de la ciencia se encuentra de tal forma estructurado, que en el estado de la actual investigación, por ejemplo, de la ciencia genómica, no sea muy probable encontrar discusiones sobre la actual crisis financiera, a no ser bajo la forma de temas marginales que poco afectan el alcance y desempeño de la disciplina. Tal y como señala Luhmann: "Las estructuras son condiciones que delimitan el ámbito de las operaciones con capacidad de enlace, es decir, son condiciones de la autopoiesis del sistema" (Luhmann 2007b:339).

Si se opta por conferirle un peso determinante a las influencias o condicionantes que se encuentran perturbando al sistema de la ciencia, entonces se tendrá que hacerlo tomando en cuenta el siguiente punto: la ciencia mediante la determinación estructural establece contactos con su entorno mediante una sutil complicidad intersistémica que ya hemos mencionado antes (y que ampliaremos aquí), es decir, mediante el acoplamiento estructural.

La determinación estructural se realiza por medio de un acoplamiento constate con las condiciones del entorno (en el caso de la comunicación científica, por ejemplo con estados mentales de los individuos participantes). Pero ello no altera nada el hecho de que el sistema únicamente puede adoptar estados que corresponda a su estructura y que al mismo tiempo sea capaz de transformar estructuras solamente por medio de operaciones propias.

Finalmente, la configuración de estructuras obedece a un proceso dinámico, por lo que no se puede pensar en estructuras estacionarias sin capacidad de transformación. De hecho, según el propio Luhmann, las estructuras emergen principalmente como resultado de un proceso evolutivo en donde adquieren su unidad a partir de la diferencia entre variación y selección. Las estructuras seleccionan la comunicación que satisface la capacidad de enlace del sistema, de esta manera producen expectativas que se cumplirán o no, y sólo en esta medida, el sistema posteriormente podrá reconocer una variación. Además, las estructuras deben permanecer disponibles más allá del instante en el que se presenta una comunicación o un pensamiento y poseer una cierta duración, que sin embargo no está fincada en el tiempo, sino que sólo hace posible el paso de una operación a otra, generando una estabilidad dinámica (Corsi et al. 2006:97 y s.). Sin esta condición, el sistema no podría llevar a cabo la autopoiesis, no podría reconocer su operación propia ni lograría una autonomía frente al entrono, en otras palabras, el sistema se disolvería.

En resumen decimos con Luhmann: “Todas las características hasta ahora mencionadas, la autonomía y la cerradura operativa, la codificación binaria y la inclusión selectiva, (y con ello 
también la sucesión de un gran incremento en la capacidad de disolución y recombinación) ${ }^{16}$ contribuyen a que la ciencia sea un sistema parcial de la sociedad" (1996:256).

\section{Reducciones correctas}

Hasta este punto, hemos tratado de exponer algunas de las condiciones que hacen de la ciencia un sistema social. El presente subtítulo puede ser ligado como una continuación del anterior, ya que en él se abordan elementos intrínsecos a este sistema, más aún, este puede ser considerado como uno de los apartados en donde la ciencia aparece con mayor énfasis y con mayor nitidez: llegamos al subtítulo de las reducciones correctas.

Una reducción es siempre reducción de complejidad. Los sistemas reaccionan ante las irritaciones del entorno con selección mediante estructuras, de ahí que la reducción de complejidad se lleve a cabo en un nivel estructural. No obstante, Luhmann hace la acotación de que la primera reducción, es decir, la más abstracta, tiene efecto en el nivel operativo de la propia distinción.

"La primera reducción de complejidad que propiamente no logra, como tal, una reducción se encuentra en el momento en el que se lleva a cabo una selección de una distinción" (Luhmann 1996:270).

Se dice que esta primera reducción no logra propiamente una reducción, por el hecho de que la distinción únicamente lleva a cabo el desplegar una forma de dos lados al alcance de quien observa, de ahí que la distinción por sí sola no arroja una reducción: "La distinción comienza un proceso de la construcción de la complejidad mediante una reducción de la complejidad, que como pura distinción todavía no logra ninguna reducción" (Luhmann 1996:271).

Más bien, las reducciones suponen una condensación de selecciones. Parten del hecho de una selección condensada; se constituyen a modo de estructuras, y en sus operaciones han reducido una buena cuota de complejidad. Si lo presentamos como una "repetición del señalar" entonces las estructuras condensadas se convierten en invariantes más o menos estables que hacen surgir ideas de estados, géneros, términos etcétera, es decir, aquellas designaciones que en un nivel muy básico nos permiten señalar a los árboles como árboles, y no arbustos, y en otros niveles, señalar "alcanos" a diferencia de "alquinos".

Ante esto, en una teoría de la ciencia, y más aún, en una teoría del conocimiento que acepta que la formación de designaciones tales como casas, perros, cielo, tierra, materia, etc., están sujetas al marco operativo de la observación y la distinción, resultaría válido preguntar por las causas originales de esto, o más allá, por una "distinción originaria".

Según la teoría de sistemas, buscar una causa sui aristotélica queda subvertida al razonamiento de la re-entry según el concepto de Spencer Brown. ${ }^{17}$ Entonces el supuesto inicio se desvanece, dando paso a la simultaneidad de la re- entrada, ya que ésta hace que la distinción se presente de manera doble: como punto de partida de una distinción y como distinción en aquello que, a su vez, ha sido distinguido.

Siguiendo un ejemplo de Luhmann, durante el siglo XIX la filosofía política formulo la distinción moderna entre Estado y sociedad, la cual es al mismo tiempo el principio constitutivo del Estado. Otro ejemplo sin lugar a dudas es esta misma teoría, cuando al hacer

\footnotetext{
${ }^{16}$ El tema de la disolución y la recombinación fue deliberadamente excluido de la investigación por razones de tiempo y espacio, se ruega al lector su comprensión.

17 El cálculo de la forma de Spencer-Brown se inicia haciendo una distinción; el método funcional se basa en la comparación de alternativas equivalentes; la contingencia remite a otras posibilidades (...) Todo el bagaje conceptual de la teoría tiene por centro la diferencia. Rodríguez, 2007:XIV
} 
la distinción directriz entre sistema y entorno, se señala que ésta al mismo tiempo es la condición de emergencia del sistema (y del entorno por ende).

Estas son algunas de las condicionantes de las reducciones. En lo que sigue trabajaremos con la más significativa para el sistema de la ciencia: el concepto.

\subsection{Concepto científico}

En primer lugar, Luhmann define los conceptos como "ultraelementos estructurales", es decir, se trata de señalamientos fijos para la construcción de expectativas en situaciones determinadas.

"Los conceptos son, con otras palabras, condensaciones y condensadores de expectativas que confieren estructura a la comunicación científica en su permanente proceso de autopoiesis" (Luhmann 1996:277). Como un desempeño netamente estructural (autorreferente), los conceptos se tienen que repetir para ser confirmados como tales, de ahí su alto grado de generalidad.

La ciencia no puede observar nada que no se pueda conceptualizar. De hecho, mediante el uso de los conceptos, la ciencia puede hablar de un entorno, sin siquiera establecer un contacto con él. Por ello también decimos que los conceptos tienen la función de crear al mismo tiempo una complejidad interna al propio sistema, como también una reducción de complejidad en el interior del mismo: así como las palabras crean y reducen la complejidad del sistema social: (los conceptos) se emplean para posibilitar la secuenciación permanente de: complejización, simplificación, complejización, simplificación...n. ${ }^{18}$

Nunca estará de más reforzar la premisa epistémica de esta teoría, la cual hace hincapié en que el concepto no se refiere a una fiel representación de la realidad, ni mucho menos a una semejanza, sino a estructuras que como resultado de la operación recursiva, sirven para la complejización del sistema, así como también, a la reducción de complejidad. Nada más pero nada menos.

Por otro lado, en el tema del concepto científico y su demarcación frente al lenguaje cotidiano podemos encontrar una rica fuente de discusión histórica, lo que nos remite a las condiciones del surgimiento de un sistema de función diferenciado como la ciencia. Por muchos años, las palabras de la jerga coloquial resultaban así mismo pertinentes en el lenguaje especializado de la ciencia y la filosofía. De hecho estas palabras pertenecen a un ámbito comunicativo más grande, ya que mediante ellas se realiza la autopoiesis del sistema social en su conjunto, y a causa de esto lograban infiltrarse en otros subsistemas. No fue sino hasta el surgimiento de la organización estratificada que sostuvo a la tradición escolástica, que el lenguaje empleado por la ciencia comenzó a diferenciarse del lenguaje de las nacientes lenguas "vulgares", Ilegando a tal punto que fue convirtiéndose en un asunto de exclusividad; baste recordar el uso reservado del latín tanto para la iglesia como para las universidades. De aquí que la "reconceptualización" de las palabras constituya un momento importante para la diferenciación de la ciencia en la sociedad.

La variación epistémica de esta teoría, acentúa que al hablar de los conceptos no hacemos referencia a una verdad definitiva, ni tampoco a un error comprobado con el exterior. Los conceptos, para decirlo nuevamente: sólo son instrumentos que se manifiestan cuando se trata de llegar a la designación de verdad o falsedad. Los conceptos no son signos que designan al mundo exterior, su verdadera función reside en la reproducción autopoiética de una comunicación específicamente científica, poniendo a disposición del sistema un principio de limitacionalidad.

\footnotetext{
${ }^{18}$ Como también lo ha expresado Edgar Morin: “simplificación - complejización”, en el estudio citado, Tomo I p. 63.
} 
Limitacionalidad por otro lado, también implica la formación de conjuntos organizados que son de muy diversa índole, en donde los diferentes conceptos en y a cerca del mundo establecen relaciones de prestación, acoplamientos e irritaciones continuas entre sí. Estos cuerpos se representan por los programas, que veremos a continuación.

\subsection{Programas}

Si los conceptos todavía no alcanzan a reconocer que determinadas operaciones puedan ser tratadas como verdaderas o falsas, ni alcanzan a construir oraciones, proposiciones o corpus teóricos para tal fin, entonces es necesario echar a andar otro tipo de distinciones. Para establecer dichos criterios, el sistema necesita de programas.

Siendo congruentes con lo planteado, por paradójico que parezca, la verdad - como un lado más del código científico verdadero/no verdadero- no es el valor superior del sistema y en sí mismo no constituye un criterio suficientemente instructivo para alcanzar la propia verdad. Por esto, el sistema necesita echar a andar programas que seleccionen qué tipo de conocimientos deben ser adjudicados al valor de verdad del propio código.

Desde el punto de vista del contenido, la programación no es otra cosa que el llevar a cabo la limitacionalidad. "Los programas deben formular de tal manera las condiciones de lo correcto, independientemente de los contenidos, que las operaciones puedan enlazarse continuamente" (Luhmann 1996:289).

Los programas se definen entonces como una regla de disposición que se encarga de regular el valor positivo/negativo del código al modo de correcto/incorrecto. También, estos, así como otros elementos de la teoría de sistemas, se encuentran por así llamarlo "heridos" por una distinción que divide la unidad en dos partes. Así, la binarización de los programas arrojará una nueva diferenciación: la diferenciación entre teorías y métodos.

Esta diferencia tratará de explicar la función de los programas como - guías de la verdad al interior del sistema de la ciencia- . Vayamos a exponerlos.

\subsubsection{Teorías}

Las teorías, al igual que los métodos, cumplen la función en la ciencia de la desparadojización del sistema, es decir, de cómo es posible manejar lo indeterminado con tal de que se transforme en determinado y así se pueda destautologizar la autorreferencia.

Las teorías están compuestas de afirmaciones (comunicaciones) en la forma de enunciados (...) "son formulaciones (incluyendo las afirmaciones sobre los conceptos), y esto aun en el caso de que no exista ninguna referencia empírica" (Luhmann 1996:292).

La función de las teorías, a diferencia de los métodos como veremos adelante, no toma en cuenta las formulaciones autorreferenciales, por ello las teorías se convierten en asimetrías del sistema, es decir, establecen una heteroreferencia respecto del código. Su contenido enunciativo hace referencia a propiedades, cualidades, estados y demás descripciones sobre un contenido condensado (objeto) distinto a ellas mismas, por eso se dice que las teorías hacen referencia a cosas ajenas, objetivas. Esto no quiere decir que establezcan un contacto ideal con el entorno, ni que lo representen ni que lo simbolicen, de ahí que: "No es el objeto el que garantiza la unidad de la teoría, sino la teoría la que asegura la unidad del objeto, medido según el principio de que todo lo que para un sistema autopoiético funge como unidad sólo puede ser producido mediante la unidad del propio sistema autopoiético" (Luhmann 1996:293). Por eso el contenido de la teoría sólo describe el cómo un sistema se refiere al mundo externo, desde el interior del sistema mismo. 
A continuación enlistaremos algunas de las funciones generales de las teorías en el sistema científico.

1) Las teorías permiten la comparación: Como reducciones correctas de complejidad, las teorías permiten establecer puntos de vista específicos para comparar características entre otros cuerpos teóricos. El trabajo teórico entonces se esfuerza por establecer comparaciones cada vez más sorprendentes, y que constantemente confirmen o refuten las viejas teorías. ${ }^{19}$

2) Las teorías sirven para aclarar el mundo en un modo muy particular: no lo hacen develando relaciones causales, ni leyes invariables, sino que logran para la ciencia una mayor capacidad de enlace y una mayor ganancia de complejidad interna. Es decir, en todo caso no se ganaría claridad al conocer más sobre lo que es un determinado objeto, sino cómo la ciencia enlaza información, razona conceptos y produce enunciados, es decir autopoiesis científica: "como si el planeta Venus después de Newton fuese un planeta mejor conocido" (Luhmann 1996:295).

3) Existen teorías que por sus propias dimensiones y pretensiones se constituyen como teorías universalistas: Una teoría universal se constituye como tal en cuanto a que los principios que postula frente a lo que observa trae consecuencias para ella misma, como el caso de una teoría como ésta que observa a través de la diferencia entre sistema y entorno. Esto no quiere decir que sólo pueda existir una sola teoría universal, ni que las demás disciplinas tengan que subordinarse a sus principios; las teorías universales lo son únicamente por su gran capacidad de autorreferencia.

Las teorías también pueden ser entendidas como redundancias informativas, que en su enlace de comunicación en comunicación producen descripciones complejas. Sin embargo, poco o nada hemos dicho sobre la cuota de verdad que viene aparejada a las teorías. En ese sentido, para poder expresar la validez del código binario son necesarios programas de otra clase, es decir, hace falta reconocer métodos.

\subsubsection{Métodos}

Los métodos se constituyen como la observación de la observación de los programas del sistema de la ciencia, por ello representan una autorreferencia en el nivel de las observaciones de segundo orden.

Los métodos dan a conocer las condiciones que se deben seleccionar si se quiere decidir entre dos valores del código (...) "Los métodos no tienen otro fin que conducir a una decisión entre lo verdadero y lo falso" (Luhmann 1996:297).

Los métodos se pueden agrupar en conjuntos más cohesionados y articularse como metodologías. Su punto de partida es considerar con la misma probabilidad el que todo sea o bien verdad o no verdad, no obstante, ninguna cosa en sí es totalmente verdadera o totalmente falsa, de ahí que un sistema no pueda conocer verdaderamente al mundo. Se trata más bien de una diferencia de grado, matizada.

Los métodos conducen las probabilidades a uno de los dos lados de la distinción y se agrupan en diferentes funciones:

1) Existen reformulaciones que contribuyen a la aclaración de las teorías, para ello, la metodología emplea mediciones: la función de las mediciones consiste en importar datos cuantitativos a las aclaraciones teóricas mediante comparación de magnitudes alcanzadas a percibir por distinciones. De ahí que la medición en la ciencia está por decirlo así,

\footnotetext{
${ }^{19}$ En ese sentido, los principio de novedad y sorpresa también son elementos imprescindibles para la autopoiesis del sistema.
} 
subordinada a sus aportaciones a las teorías, por ejemplo: no medimos el nivel del mar sino para confirmar o refutar las teorías sobre el calentamiento global y el riesgo que esto supone.

2) Los métodos también deben presuponer tiempo-secuenciación, es decir, tienen que estar en capacidad de reconocer un antes y un después. Sólo así, la metodología puede tornarse reflexiva. En sociología por ejemplo, el avance en la investigación teórica así como las nuevas proposiciones dependen de la previa revisión de los autores con los que se está discutiendo, para lo cual existe un antes y un después.

3) La metodología como respuesta a la tensión que se genera entre un esquema problema/solución, posee una organización que de alguna manera, se asemeja a la organización del propio sistema. Esta organización se traduce en proyectos: la organización exige que todo lo que comienza tenga un fin. Por eso aquí los proyectos tienen que ver también con una cuota de temporalidad. Todos los proyectos han de ser autorizados como un complejo de operaciones destinadas a resolver un problema, de ahí su pertenencia a los asuntos metodológicos.

En suma, tanto teorías como métodos son parte del desdoble de los programas que la ciencia utiliza para reproducirse y para comprobar sus propios pasos. Por encima de la oposición mutua que aparentemente se da entre ambos conceptos, los métodos y las teorías pueden estar a disposición los unos y los otros. Cuando por ejemplo, para resultados divergentes de la investigación no se puede dar una declaración que satisfaga, la diferencia será explicada como distinción empleada en cada uno de los métodos. Pero también es válido lo contrario: a los datos ya conocidos y que no están a discusión se les puede encontrar otra perspectiva mediante un cambio en el marco de la interpretación teórica.

Ambos conceptos contribuyen a lo que muchos científicos y epistemólogos de la llamada escuela racionalista (Mario Bunge por ejemplo) sostienen como aquella evidencia fáctica que hace que la ciencia quede claramente diferenciada respecto de otro tipo de conocimientos, digamos, más elementales; nos referimos al elemento de la comprobabilidad (testability) (Bunge 2000:34). ${ }^{20}$ Cada experimento pone a disposición los pasos para que éste pueda ser replicado por cualquier científico, por lo que este principio cae mejor en el dominio del método, como una suerte de "biografía del conocimiento". Sin embargo, la comprobabilidad no es ni una receta ni una regla, sino que se trata de un acoplamiento necesario entre métodos y teorías.

Pero ¿por medio de qué vía se canalizan estos programas al interior del sistema? ¿Cuáles son las vías por las que estos logran objetivarse? La respuesta como veremos, será mediante las publicaciones.

\subsection{Las publicaciones como capacidad de enlace del sistema de la ciencia}

Las publicaciones según el autor, son la moneda de cuenta corriente para el sistema de la ciencia. Ellas llevan a cabo los enlaces comunicativos del sistema científico, ya que “...sólo mediante la ayuda de las publicaciones los resultados científicos serán capaces de ser citados y de esta manera se les confiere una posibilidad limitada de enlace" (Luhmann 1996:309).

En primer lugar, las publicaciones implican necesariamente un momento histórico determinado por la aparición de medios técnicos para la impresión de libros y tratados, es decir, de la alfabetización y la impresión de textos en masa. Por ello, la aparición de la

\footnotetext{
${ }^{20}$ Como dato, en la introducción el autor también declara: “...sigo siendo un realista, cientificista, materialista, y sistemista convicto y confeso. No me ha hecho mella la contrarrevolución anti-cientificista iniciada por Thomas S. Kuhn y Paul K. Feyerabend".
} 
imprenta marca un hito en la creación, difusión y administración del conocimiento. En segundo lugar y como consecuencia de lo anterior, las publicaciones suponen un acoplamiento estructural entre diversas actividades que no necesariamente pertenecen a la operación de la sociedad, como la impresión de textos, el oficio tipográfico, la difusión y la comercialización, etcétera.

Las publicaciones ponen al alcance conocimientos nuevos para una comunidad científica, archivan y administran los conocimientos nuevos y los ya consolidados. En relación a las publicaciones de difusión científica, aquí únicamente nos referiremos a las que son de carácter especializado, tales como los distintos Journals, Science, Nature, Cell, etcétera. Sin dejar de lado, por supuesto las publicaciones en libros y tratados.

Las publicaciones tienen la característica de ser la fuente de referencia principal de los investigadores. En ellas se encuentran plasmadas las condensaciones logradas por una disciplina, organizadas en distintos temas y a partir de muy diversos enfoques. Podemos decir que de ellas surge la materia prima de la ciencia, ya que de ahí se nutre la discusión para las futuras investigaciones.

Las publicaciones no garantizan al sistema la misma cuota de enlace, al contrario, solamente aquellas que logren afianzar una condensación que provoque una reacción más fuerte en el sistema, es decir, que llamen lo suficiente la atención; que de sus páginas se retome una gran cantidad de conceptos, teorías y métodos en investigaciones posteriores; tanto en la consecuencia de ser verdaderos como falsos, podrán aportar una mayor capacidad de enlace. Esto quiere decir, que las publicaciones que le resulten indiferentes al código (ya sea por su poca consistencia o que consideran otras operaciones) pasarán desapercibidas.

Por lo tanto, "En la medida en que las nuevas propuestas se integran en un contexto teórico mayor y se toma en cuenta la vista panorámica del nivel actual de la investigación, y en la medida en que también registran y toman en cuenta sus repercusiones en las investigaciones más marginadas, los conocimientos expuestos a la comparación ganan y conservan su estabilidad" (Luhmann 1996:415), haciéndolo mediante las publicaciones.

Las publicaciones contienen la fuente de las discusiones científicas. Con frecuencia, los enfrentamientos científicos tienen lugar a raíz del contenido de una publicación (en este caso, puede presentarse también como una ponencia ante un auditorio con lo que se convierte simultáneamente en un asunto de la interacción), en donde se esgrime una serie de condensaciones que terminarán por suscitar una argumentación, tema de nuestro siguiente apartado.

\subsection{Argumentación}

Se argumenta cuando se tiene una objeción o se confirma un concepto, una teoría o un método, generalmente contenidos en una publicación. Por ello decimos que la argumentación es el llevar a cabo una comunicación que toma en cuenta todos los elementos anteriores; sin jerarquías ni gradación de niveles prioritarios; nuevamente, pura autorreferencialidad.

Por ello, la argumentación se consuma a partir de una diferencia: la diferencia entre la redundancia y variedad. La redundancia constituye la forma en la que la comunicación se enlaza, mediante ganancia de seguridades conforme a la postulación de principios. "El concepto de redundancia se refiere al observar y al describir los objetos sólo en la medida en que puedan ser observados y descritos. Por tanto se sitúan en el nivel de observación de segundo orden" (Luhmann 1996:313).

Mientras la variación representa todos aquellos elementos con los que el sistema aumenta su apertura hacia el entorno. "Entre más turbulento sea el entorno para el sistema, y entre más 
fuerte el sistema haga coincidir sus propios acontecimientos con los del entorno, más grande puede ser la variedad" (Luhmann 1996:315).

De esta manera, la argumentación se presenta como el proceso operativo que tiene la tarea de equilibrar la variedad y la redundancia, de ahí que combine lo conocido con lo desconocido. Por ello, en la argumentación suceden los patrones de las comunicaciones científicas que producen novedad (variación) y/o consolidan lo sabido (redundancia), todo ello en función de encontrar mejores soluciones combinatorias.

Los científicos cuando argumentan no hacen sino utilizar redundancia y producir variedad, y a la inversa, pero también, para poder hacerlo deben de valerse de una aclaración, y es mediante ello que la argumentación se torna reflexiva. La aclaración puede entenderse también como una reformulación que hace el sistema acerca de sus propios productos, como un tipo de evaluación, en donde cualquier modificación será una modificación válida para el mismo sistema; Luhmann incluso llega a señalar que debido a esto, las leyes de la naturaleza no son más que "deberes autoimpuestos" que se comprueban en los propios términos del sistema, y no en la realidad.

Finalmente, debemos reservar un espacio para abordar el tema de las disciplinas científicas, tema que está estrechamente ligado a la ciencia como sistema, ya que pertenece al ámbito de la diferenciación; algo que bien podríamos agregar como una condición de sistemidad de la ciencia, así como también; una reducción.

\subsection{Disciplinas científicas (Diferenciación)}

"Las disciplinas son subsistemas del sistema de la ciencia, se trata pues fundamentalmente de una diferenciación del sistema mismo" (Luhmann 1996:319). Todas ellas están orientadas por el código binario de la ciencia, por lo tanto, sobre todas rige el mismo código: la misma búsqueda por la verdad.

El postulado de la diferenciación de los sistemas se sustenta en la posibilidad de repetir el código del sistema al interior del sistema mismo, generando sub unidades (sistemas) que enlazan dicho código sincronizándose con él y en él. Las diversas disciplinas como la Física, la Química, las Matemáticas y la Sociología se constituyen cada una como el entorno de cada una, esto quiere decir que cada disciplina ha establecido bordes que la definen como unidad.

En la mayoría de los casos, la diferenciación entre disciplinas responde a criterios y a prosecuciones de carácter teórico. Sin embargo, los límites de cada disciplina sólo son válidos para la disciplina misma, y no para su entorno. Nadie puede negar a ningún robótico observar a la sociedad y al mercado como máquinas no triviales. En efecto, no se trata sólo del aislamiento de campos de investigación, sino de una diferenciación de las diferencia, y de distintas maneras de reconstruir la ciencia bajo la forma de la diferencia de sistema/ entorno.

En este apartado no buscamos discutir con las teorías sobre la diferenciación del currículum, ni mucho menos con una teoría sobre la particularidad fenoménica de determinado campo y objeto de estudio, sino dar cuenta del proceso de diferenciación que subyace en el surgimiento de las diversas disciplinas en la ciencia.

Con estas reflexiones damos por concluido los apartados sobre los elementos que están en juego al interior de la ciencia. Para finalizar, haremos una breve exposición acerca de las relaciones (tan ricas histórica y sociológicamente) entre la ciencia y la sociedad, y cómo es que estas acontecen. 


\section{Ciencia y sociedad}

Llegamos así a uno de los aparatados más relevantes de la presente exposición, el referido a las relaciones de prestación entre la ciencia y la sociedad, o más concretamente, sobre la ciencia y sus relaciones con el entorno.

Se trata de un capítulo cargado de antecedentes, ya que es tradición el que la sociología haya atendido estos temas, desde muy diversas perspectivas. En Luhmann se encuentra una reformulación (variación) por demás interesante. Con lo que hemos expuesto en este resumen, tres conceptos han sido los principales referentes: observación, autopoiesis y autorreferencia (circularidad). Todos ellos apuntan a una exploración que en su base pondera la pregunta por el cómo más allá de la pregunta por el qué. De esta manera, en las relaciones entre la ciencia y la sociedad desde un enfoque sociológico-sistémico se debe hacer considerando el carácter constructivo del concepto de sociedad, así como su carácter autoimplicativo. De lo que se trata entonces no es de esclarecer las influencias de la sociedad hacia la ciencia, ni el impacto (la mayoría de las veces riesgoso) de la ciencia hacia la sociedad, dejando por separado ambos ámbitos. Lo que aquí se tiene que hacer es echar a andar la observación autoimplicada y paradójica que reconoce a la ciencia como un sistema que observa a la sociedad y al mundo, desde la sociedad y por consiguiente, dentro del propio mundo. Para ello, nuevamente, hemos elaborado un esquema de presentación con algunos de los conceptos más relevantes. Comenzaremos con los acoplamientos.

\subsection{Acoplamientos}

La mejor manera que encuentra esta teoría para dar cuenta de las relaciones que se establecen entre los diversos subsistemas, es a través de los acoplamientos estructurales.

Los acoplamientos estructurales operan enlazando comunicaciones entre sistemas diferenciados. Esto lo generan en un doble sentido, es decir, hacia el entorno de los sistemas, pero también al entorno al interior de estos. ${ }^{21}$ Por esta razón los sistemas de la sociedad se mantienen unidos, poniendo a disposición complejidad entre sí mismos por medio de dichos acoplamientos.

Las formas de acoplamiento, como pueden ser los órdenes familiares, de gobierno, institucionales, religiosos o de tiempo libre y pasatiempo, son entrecruzamientos dinámicos, lo cual quiere decir que pertenecen a un orden histórico en constante movimiento y transformación.

Los elementos que habíamos tratado en los dos aparatados anteriores contribuyen a delimitar, o más bien dicho encauzar el orden y la cualidad de los acoplamientos: si bien, la ciencia puede tematizar casi cualquier cosa, los códigos, las estructuras, los programas, los argumentos, las teorías, lo métodos, etcétera, encargados de la direccionalidad reflexiva de la autopoiesis, delimitarán con qué sistemas habrá una mayor capacidad de enlace y por lo tanto un acoplamiento un tanto más estricto y con cuáles no. ${ }^{22}$

Luhmann ofrece el ejemplo de los acoplamientos estructurales que se dan entre el sistema de la ciencia y el sistema educativo donde sobresalen las interacciones que suceden en las aulas y los laboratorios, en el que los mismos miembros de la comunidad científica fungen simultáneamente como miembros del cuerpo docente: en el caso de los científicos con estudiantes de PhD, éstos evalúan y promueven actividades educativas, y al hacerlo trabajan

\footnotetext{
${ }^{21}$ Véase el particular concepto de "acoplamiento operativo" en Luhmann 2007b:625.

${ }^{22}$ En términos de investigación sociológica sería pertinente enlistar cuáles son los contactos entre los acoplamientos existentes, y los que se pueden observar, así como también en qué consisten cada uno de estos.
} 
para tales fines con un código distinto al de la ciencia (en el sistema educativo se refiere, pese a la controversia en esta materia, a la educación/selección). ${ }^{23}$

Otro ejemplo es el caso del acoplamiento entre la ciencia y la política, un caso por demás interesante ya que están en juego temáticas que han sido de tradicional interés para la sociología (Estado, seguridad, planeación, inclusión/ exclusión, poder, gobernanza, etc.)

Los gobiernos del mundo enfrentan un riesgo global que en gran medida ha sido desatado por los avances en la ciencia y la técnica. El ejemplo es fresco y se refiere al multicitado "calentamiento global", en donde los gobiernos han tenido que invertir en grandes proyectos de investigación científica para visualizar los riesgos y generar estrategias de prevención, si es que desean garantizar condiciones de seguridad interna, gobernanza entre la ciudadanía y estabilidad económica, lo anterior como resultado de una amenaza autogenerada, surgida a partir de la confianza sin miramientos en la ciencia, "panacea del progreso". Por esta razón, sigue siendo muy elevada la demanda de científicos en colegios asesores: la "expertocracia" al servicio del poder.

“Por un lado, en la comunicación se deben mantener en reserva las inseguridades todavía presentes en la ciencia o por lo menos restarles importancia; por otro lado, deben evitar decidir previamente las preguntas políticas como si fueran preguntas por el saber" (Luhmann 2007b:623).

En el caso del acoplamiento con la política subyace una tensión sumamente interesante, materia para futuras investigaciones. El hecho de que la ciencia trabaje con inseguridades y la política lo haga totalmente a la inversa, ha generado una tensión paradójica que acarrea contingencia en los resultados de tales acoplamientos: simplemente no se puede esperar que un científico haya aparecido en el pleno de la Cumbre Climática de Copenhague mostrando "dudas metódicas" sobre el tema del calentamiento global, ya que las presiones sobre estas decisiones no descansan sobre el defraudar a la verdad, sino a grupos de presión y supuestamente, a la vida misma, por lo tanto, de él serán exigidas sólo seguridades.

Los científicos implicados en las universidades, al igual que en tareas políticas, combinan los lineamientos dictados por el código de la verdad/no verdad con aquellos de la pedagogía y del poder (o la política), en donde en raras ocasiones se han logrado justos medios y donde también muchas veces han surgido problemas de prestación.

La tarea del investigador (sociólogo) reside entonces en determinar las fronteras de los sistemas a través de sus operaciones específicas, y no dejarse confundir con lo que los sistemas procesan y lo que los sistemas están prestando para realizar funciones equivalentes. Esto por medio de la observación de los acoplamientos estructurales.

\subsection{Ciencia básica / ciencia referida a la aplicación}

El tema de la ciencia básica y la ciencia referida a la aplicación retoma una inquietud que tampoco es nueva en los estudios sociales de la ciencia. ${ }^{24}$ En una nota al pie, Luhmann explica esta distancia respecto del término "aplicado" optando el término "referido a la aplicación", ya que: “...no se trata de la aplicación de resultados del sistema de la ciencia al exterior de sus límites, sino de la investigación dentro del sistema de la ciencia misma que sólo reflexiona sobre las posibilidades de aplicación y las simula eventualmente" (Luhmann 1996:451).

\footnotetext{
${ }^{23}$ Determinación del código según como lo plantea Giancarlo Corsi en su trabajo citado sobre el proceso de reforma del sistema educativo.

${ }^{24}$ Desde los ya clásicos estudios de Karl Mannheim, hasta los estudios de la teoría del actor-red (ANT), pasando por estudios sistémico-constructivistas de autores como Michael Mulkay, Karin Knorr-Cetina, Michael Schillmeier, Steve Woolgar y Barry Barnes, entre otros.
} 
La diferencia entre la ciencia básica y la ciencia referida a la aplicación se asemeja al plano de la función y la prestación: la ciencia básica en este sentido, le es completamente funcional al sistema científico en general, ya que en ella suceden todas la operaciones necesarias que hemos expuesto, mientras, la ciencia referida a la aplicación representa un emergencia, digamos, lateral y se establece así como una prestación (accidental) al entorno científico.

El plano de la ciencia referida a la aplicación es el más susceptible de ser cuestionado por el entorno de la ciencia, ya que de ahí surgen las comunicaciones estilizadas a modo de divulgación que más impacto generan y que son más asimilables para los observadores circundantes. De ahí el creciente interés por los problemas advertidos por la ciencia y la consecuente sed de explicación y solución de una porción cada vez más grande de la opinión pública.

\subsection{Relaciones de prestación de la ciencia a la sociedad}

La ciencia establece relaciones de prestación con la sociedad de muy diversa índole. Podemos referir el aspecto "injerencial - interventor" de los postulados científicos hacia con los "problemas" en la sociedad. ${ }^{25}$

De esta manera surgen desarrollos tecnológicos que en el plano de la materialidad se concentran en resolver dificultades prácticas en diversas actividades sociales. También en los planos interpersonales, la técnica se traduce al ámbito de la terapia, así mismo, encauzada a resolver dificultades y conducir las selecciones de los individuos en cuestión.

Estos dos aspectos de la intervención presentan a su vez sus propias dificultades cuando se comprende que la ciencia no establece contactos punto por punto con el entorno, sino que a lo sumo, ella misma genera sus propias condiciones en las que lo proyecta. Así las cosas, en las relaciones de prestación de la ciencia destinadas a resolver contrariedades (las cuales la han acompañado desde sus orígenes) lo que subyace es una proyección, que lleva a plantear anomalías, fallas y pendientes qué atender y sobre los cuales investigar, acompañados por supuesto de sus posibles soluciones.

Entonces en el plano de la ciencia aplicada ¿Será entonces que los temas de investigación científicos deban ser entendidos más bien como deberes autoimpuestos? ¿Que el genoma humano como problema de investigación poco (o por accidente) le deba al contacto real con la naturaleza, y más bien le tenga que reconocer sus fuentes de irritación a la tradición científica de la cual surge? Sucede algo muy similar con otras disciplinas.

Y en el caso de la ciencia referida a la aplicación como prestación del sistema ¿el éxito y funcionalidad en sus recetas, recomendaciones, sugerencias y demás disposiciones se deben más bien a consecuencias no esperadas que a estrategias racional y lógicamente planificadas? El hecho de que una compleja planta de refinamiento petrolero funcione mediante principios de química orgánica teórica, se debe más bien a un accidente (en el sentido de contingencia) que una adecuación del tipo causal- racional.

No obstante, generalmente cuando se le pregunta a la ciencia sobre la resolución de problemas y necesidades sociales, dependiendo el grado de reputación y desarrollo de la disciplina, ésta puede emitir prescripciones sobre dichas urgencias, obteniendo en muchos casos resultados que dejan satisfechos a los involucrados. Por ello, a estas alturas y tomando en cuenta el prestigio alcanzado por la ciencia en nuestra sociedad, resulta muy arriesgada la opinión que dice que la ciencia no devela la realidad, sino que en todo caso, la construye.

\footnotetext{
${ }^{25}$ Traemos a colación nuevamente el caso de las reformas educativas en el citado estudio de Corsi 2002. Especialmente el Tercer Capítulo.
} 
Al aceptar esta idea, también debemos aceptar el hecho que ante una realidad construida, también los problemas, las soluciones, las leyes, su aplicación, las recomendaciones y sus éxitos no son otra cosa que resultados que dé ante mano van implicados en todo momento en el proceso de la investigación.

La idea del contacto pleno con la realidad, del descubrimiento, es decir, de que el mundo y la naturaleza se encuentran ahí, esperando pacientes al científico para que actúe como su interlocutor y emita pruebas y leyes, no hace más que conducirnos a un debate estéril y sin mayores rendimientos, según como se ha empeñado en mostrar esta teoría. Todo esto no debe escandalizar, si se parte de una idea del mundo, que, como ya lo han apuntado algunos autores en esta investigación citados, ha dejado la unidad para afrontar la diferencia.

Por último, pero no por ello menos importante, un plano más de prestaciones de la ciencia y la sociedad (y viceversa también) es el concerniente al terreno de la moral, de la ética y de la responsabilidad.

Frecuentemente se llevan a cabo debates sobre diferentes éticas en la práctica científica. Desde la ética del modo de citar, hasta la ética hacia los resultados de la investigación y sus consecuencias para el bien del "proyecto de la humanidad". Para estos temas reproducimos una cita textual del autor: "Ningún sistema puede resumir y juzgar su historia en el punto final de un espíritu y tampoco puede considerarlo como bueno o razonable. Con cada paso que se abre de nuevo la alternativa de aceptar y rechazar. Y por eso sería demasiado arriesgado intentar la constitución de un juicio global acertado sobre el sistema en un sentido racional o moral" (Luhmann 1996:489).

Enlazamos así nuestro último subtema.

\subsection{Autoridad revaluada}

Las ideas anteriores conducen a pensar en un mundo que ha perdido su centro, jerárquico, omnisciente, panóptico desde el que se dominaban todas la perspectivas. En su lugar emerge un mudo complejo, cargado de contingencia, en cuya descripción se encuentra el ejercicio de trazar distinciones. Por esta razón, la idea de la autoridad, más allá de perderse definitivamente, se debe adecuar a este razonamiento.

Para empezar, la autoridad utiliza argumentos, los cuales se pueden ofrecer a través de la interacción mediante la palabra o la tele- presencia de la escritura. Si de lo que se trata es de esgrimir un argumento con una intencionalidad marcada, entonces lo que tradicionalmente se hacía era preguntar por ¿quién lo ha dicho? ¿de parte de quién? o ¿por cuáles razones?. Esta inquisición se hacía pensando en un sujeto - dígase genio o figura- cuya reputación debía ser conocida para poder corroborar la verdad de su afirmación (por eso, la verdad venía cargada de una cuota de autoridad ${ }^{26}$, la autoridad se desprende del conocimiento acreditado de un sujeto particular (sujeto en el sentido de persona u organización, etc.).

En la modernidad la autoridad recayó en las figuras ligadas al poder, cuya moneda de cuenta corriente siempre fue la verdad o la certeza. La iglesia conoce la verdad, realiza la interpretación última de la palabra de Dios, y con ello estimula una coacción sobre su comunidad. El príncipe debía estar bien asesorado si es que quería conservar su reino (Maquiavelo), tiempo después las Universidades y los colegios empiezan a ser el receptáculo del conocimiento liberal e ilustrado, con lo que le rebaten una cuota muy importante de autoridad a la religión, teniendo como parangón el siglo XVIII, donde más cerca estuvo el mundo secular de arrebatársela a la longeva Institución.

\footnotetext{
${ }^{26}$ Véase para tal fin la idea sobre el conocimiento y su valoración en La verdad y las formas Jurídicas de Michel Foucault. Tiresias, el viejo campesino, al ser el testigo del asesinato de Layo y llamar a la evidencia manifiesta (a pesar de su ceguera) se convierte inesperadamente en una figura de autoridad frente al mismo rey.
} 
Sin embargo, en los casos anteriores, bajo la etiqueta de modernidad, según la clasificación histórico- evolutiva de la teoría de sistemas, ya la diferenciación por funciones exigió ciertos cambios en el rendimiento de la idea de la autoridad y con ello, también en la de sujeto.

La teoría de sistemas no puede partir del mismo punto para reconocer autoridad. Como hemos visto, el sujeto como obstacle épistémologique es sustituido por la noción de la operación-observación. Asumiendo esto, entonces la autoridad, en primer lugar debe quedar enmarcada bajo la autopoiesis específica de la ciencia; en segundo lugar, debe establecer una observación de segundo orden, mirarse a ella misma y establecer cuáles son aquellos enlaces comunicativos que generan autoridad al interior del sistema (en sus asociaciones, entre profesores, entre profesores y alumnos, entre academias, etcétera) y hacia el exterior como resultado de acoplamientos estructurales. Por lo tanto para reconocer autoridad no hay que observar a los sujetos sino a aquel proceso que hace surgir a los sistemas. ${ }^{27}$

Una distinción más con respecto al análisis de la autoridad se basa en el tema de la jerarquía, lo cual enlaza propiamente el problema de nuestro aparatado, ya que este concepto en la teoría aparece, como vimos, en letras rojas.

En el apartado respectivo sostuvimos que la jerarquía experimentó un proceso en dirección hacia la funcionalización, en donde el concepto se hizo cada vez más dinámico y abierto para albergar funciones diversas. Su transición hacia la diferenciación por funciones trajo aparejado un gradiente de complejidad que arroja una lógica policontextual.

Precisamente este último concepto marca la diferencia entre una concepción de autoridad jerárquica y una funcional. La diferenciación por funciones hace surgir estructuras dinámicas, que sustituyen estabilidad densa por polifuncionalidad, esto genera que una gran variedad de sistemas se procuren para sí mismos una descripción del mundo, de la naturaleza y de la sociedad en donde observan y operan (viven) llegando a ser tan válida en tanto logren establecer capacidad de enlace de manera exitosa. Prueba de ello será el logro de sus autopoiesis y por ende su continuidad como sistemas.

Ante todo esto queda la sensación de una ciencia deflacionaria, venida a menos. Todo lo contrario, la ciencia opera con un código diabólico: ¡se ha dado la tarea de observar a Dios! Pocos sistemas sociales son capaces de operar con una observación tan paradójica, podría decirse trágica, y prolífica a la vez. La ciencia es el sistema de la complejidad y la paradoja por antonomasia, y las aproximaciones hacia ésta no deben perder de vista dicha cualidad, por lo tanto deben conducirse con la debida precaución. La ciencia, comparte opiniones con las observaciones de otros sistemas que también ofrecen descripciones sobre el mundo, como la vida cotidiana (si es que es sistema), la religión o el arte, sin embargo, como celosa poseedora del código de la verdad/no verdad, cada uno estos y todos los demás sistemas tendrán que voltear, al menos de reojo, a ver qué se está haciendo en los laboratorios, en los institutos y en las academias, ya no más con ojos de quiliasta, sino con una mirada de autocomprensión. RM

\section{Bibliografía}

Bunge, M. (2000). Epistemología. Curso de actualización. México D.F.: Siglo XXI. [2ª Ed.].

Corsi, G. (2002) Sistemas que aprenden. México D.F.: UIA- ITESO.

\footnotetext{
${ }^{27}$ Así, para entender la naturaleza de los procesos al interior de la sociedad (y la misma teoría sociológica), en el artículo ¿Cómo es posible el orden social? Luhmann coloca como eje explicativo el proceso del surgimiento del sistema social, desplazando la atención sobre el individuo. Luhmann 2009
} 
Corsi, G., Esposito, E., \& Baraldi, C. (1996). Glosario sobre la Teoría Social de Niklas Luhmann. México D.F.: Universidad Iberoamericana, ITESO, Anthropos.

Foucault, M. (1996). La verdad y las formas jurídicas. Barcelona: Gedisa.

Heider, F. (1926) Ding und Medium. Symposion, Philosophische Zeitschrift für Forschung und Aussprache, (1),109- 157

Habermas, J. (1997). Teoría de la acción comunicativa: complementos y estudios previos. Madrid: Cátedra.

Kant, I. (2003). Crítica a la Razón Pura. México D.F.: F.C.E.

Kuhnn, T. (2005). La estructura de las revoluciones científicas. México D.F.: F.C.E. [3ạ Ed.]

Luhmann, N. (1996). La Ciencia de la sociedad. México: Universidad Iberoamericana, Anthropos, ITESO.

Luhmann, N. (1998). Sistemas Sociales. Lineamientos para una teoria general. Mexico D.F.: Anthropos, Universidad Iberoamericana, Pontificia Universidad Javeriana. [2a Ed.]

Luhmann, N. (2006a). El amor como pasión: la codificación de la intimidad. México D.F.: UIA- Antrhopos.

Luhmann, N. (2006b). Sociología del Riesgo. México D.F.: Universidad IberoamericanaITESO.

Luhmann, N. (2007a). Introducción a la teoría de sistemas de Niklas Luhmann. Lecciones publicadas por Javier Torres Nafarrate. México D.F.: Universidad Nacional Autónoma de México.

Luhmann, N. (2007b). La sociedad de la sociedad. México D.F.: Universidad Iberoamericana, Herder.

Luhmann, N. (2009). ¿Cómo es posible el orden social? México D.F.: Herder.

Mascareño, A. (2006). Sociología del Método; la forma de la investigación sistémica. Cinta de Moebio, (26).

Morin, E. (1986) El Método, Vol. 3. Barcelona: Cátedra

Platón (2009). Teeteto. México D.F.: Bibliotheca Scriptorum Graecorum et Romanorum Mexicana. UNAM.

Platón (2006). Menón. México D.F.: Bibliotheca Scriptorum Graecorum et Romanorum Mexicana. UNAM.

Rodríguez, D. (2007) La sociología y la teoría de la sociedad. En Luhmann La sociedad de la sociedad (pp. IV- XXII). México D.F.: Universidad Iberoamericana, Herder.

Sobre el autor

Gerardo D. Sánchez Romero es Sociólogo y candidato a Magíster en Análisis Cultural de la Universidad de Copenhague (KU). Entre sus últimas publicaciones se encuentran: Luxo e Sofisticação: As Metamorfoses no Consumo das Metrópoles Latino-americanas: O 
Exemplo de São Paulo (Con Jeferson Rezende) (2009) y Enredando el territorio. Google Earth y la representación geosemántica (2008)

geruzko@gmail.com

\section{Contacto}

The SAXO Institute

University of Copenhagen

Njalsgade 76, $2300 \mathrm{~S}$

Copenhagen, Denmark

Recibido: Agosto 2010

Aceptado: Marzo 2011

Artículo disponible en: http:// www.facso.uchile.cl/ publicaciones/ mad/24/gsanchez02.pdf 